\title{
ANOMALIES OF CRITICALITY
}

\author{
by E. D. Clayton
}

September 1974

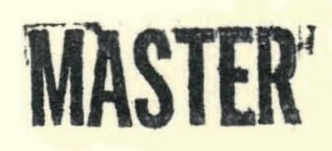




\section{DISCLAIMER}

This report was prepared as an account of work sponsored by an agency of the United States Government. Neither the United States Government nor any agency Thereof, nor any of their employees, makes any warranty, express or implied, or assumes any legal liability or responsibility for the accuracy, completeness, or usefulness of any information, apparatus, product, or process disclosed, or represents that its use would not infringe privately owned rights. Reference herein to any specific commercial product, process, or service by trade name, trademark, manufacturer, or otherwise does not necessarily constitute or imply its endorsement, recommendation, or favoring by the United States Government or any agency thereof. The views and opinions of authors expressed herein do not necessarily state or reflect those of the United States Government or any agency thereof. 


\section{DISCLAIMER}

Portions of this document may be illegible in electronic image products. Images are produced from the best available original document. 
ANOMALIES OF CRITICALITY

(BNWL-4868)

January, 1974 - First Draft

Apri1, 1974 - Revision 1

September, 1974 - Revision 2

This report was prepared as an account of work sponsored by the United States Government. Neither the United States nor the United States Atomic Energy Commission, nor any of their employees, nor any of their contractors, subcontractors, or their employees makes any warranty, express or implied, or assumes any legal liability or responsibility for the accuracy, com pleteness or usefulness of any information, apparatus, product or process disclosed, or represents that its use would not infringe privately owned rights. 
September 6, 1974

\section{ANOMALIES OF CRITICALITY - REV. 2}

Revision 2 includes six items not listed in the journal article (Nuclear Technology, July, 1974), together with certain editorial corrections and other changes for clarity.

The six items include:

- The laser-induced micro-explosion involving initiation of a supercritical event in a highly compressed, small pellet of Pu containing as little as $10^{-2} \mathrm{~g} \mathrm{Pu}$.

- Homogeneous aqueous mixtures of ${ }^{235} U$ and ${ }^{238} U$, wherein it would be possible to achieve criticality (over' 1 imited concentration ranges) with a smaller quantity of $235 \mathrm{U}$ in the form of low enriched $U$ than if the $235 U$ were in the highly enriched form.

- Interacting finite cubic arrays of metal units wherein an unmoderated array of $30.0 \% 235 \mathrm{U}$ enriched spheres might have a lower critical lattice density, and hence $235 \mathrm{U}$ mass, than an array of $93.2 \%: 235 \mathrm{U}$ enriched spheres.

- Insertion of a neutron absorbing control rod into a Pu solution sphere wherein the effect of this was to cause the assembly's reactivity to initialiy increase as the rod entered the solution.

- An apparent chain reaction which took place in the Republique of Gabonaise some 100 million years ago with low ( $3 \mathrm{wt} \% 235 \mathrm{U}$ ) enriched uranium.

- Neutron multiplication and the power reactor (four billion watts and subcritical)

Five new Figures also are provided:

Figure 2 - keff of Fractional Critical Mass vs. Critical Mass

Figure $\epsilon$ - Ratio of Critical Sphere Volume to Cube Volume (Plexiglas Reflected Assemblies)

Figure 14-Computed Critical Masses of Water-Reflected Spheres of Uranyl Nitrate Solutions (No Excess $\mathrm{HNO}_{3}$ )

Figure 15-Critical Mass and Volume of Unreflected Metal Arrays

Figure 18-Control Rod Effect on Flux Level

Other "anomalies" may be included at a later date. 


\section{ANOMALIES OF CRITICALITY}

E. D. Clayton

$\underline{\text { Page }}$

ABSTRACT

A. INTRODUCTION 4

B. COMPLEXITY OF CRITICALITY 4

1. A Triple Point of Criticality 8

2. One Mass and Four Concentrations 12

C. THE CUBE AND THE SPHERE 12

D. ADDED SCATTERERS AND MODERATION 16

1. A Point of Discontinuity 16

2. The Reduction in Mass of the Sphere 16

3. The Paradox of the Infinite Slab 19

E. DENSITY EFFECTS 20

1. External Moderation 20

2. Internal Moderation - Unbounded Regions and Multiple Infinity 22

F. CRITICALITY AND THE NEGATIVE BUCKLING CORE 24

G. THE COMPLEX REFLECTOR 26

H. THE DISSOLVER PARADOX 26

I. 235U-238U MIXTURES (CONCENTRATION OR MODERATION - EFFECT ON CRITICAL MASS )

J. ARRAY ANOMALIES 32

1. Mixed Units in Storage. 32

2. Fire (Fog, Mist, or Flooding: A Potential of Triple Criticality) 34

K. AN ODDITY OF POISON (THE CONTROL ROD AND THE SOLUTION SPHERE)

L. EVEN-N VS. ODD-N NULLLIDES - A REVERSAL OII THE EFFECTS OF MODERATION 39

M. THE INFINITE SEA CONCENTRATION 44

1. Criticality in Earth 44

2. The Universe 49

N. NATURE'S ANOMALY 50

0. SMALL MASS CONCEPTS

1. Thin Foils and Nonabsorbing Low Temperature Moderators 51

2. The Laser-Induced Micro-Explosion 52

P. BEYOND CALIFORNIUM - THE "MICRO" CRITICAL MASS

1. Beyond Californium 53

2. "Micro" Critical Mass 54

Q. THE POWER REACTOR - FOUR BILLION WATTS AND SUBCRITICAL 56

R. CONCLUSIONS 56

S. ACKNOWLEDGEMENTS

T. REFERENCES 


\section{ANOMALIES OF CRITICALITY}

ABSTRACT

During the development of nuclear energy, a number of apparent anomalies have become evident in nuclear criticality. Some of these have appeared in the open literature and some have not. Yet, a naive extrapolation of existing data, without knowledge of the anomalies," could certainly lead to potentially serious consequences. The known "anomalies" include, but are not limited to,

1. relationship between criticality in finite spheres and reflected cubes

2. effect of added scatterers on the criticality of infinite slabs

3. a small mass concept whereby criticality could be achieved with less than an ounce of fissile material in the form of a single small foil $\simeq 0.2$ mil thick

4. laser-induced micro-explosion involving the initiation of a supercritical event in a highly compressed; small pellet of Pu containing as little as $10^{-2} \mathrm{~g} P u$

5. effects of progressive water flooding on the criticality of interacting arrays of fissile materials in storage vaults

6. effect of mixing metal and fissile bearing aqueous solutions together in the same vault

7. criticality of coupled fast-thermal systems composed of siall plutonium metal spheres surrounded by aqueous plutonium-bearing solutions

8. criticality of slightly enriched uranium and the negative buckling core

9. homogeneous aqueous mixtures of ${ }^{235} \mathrm{U}$ and ${ }^{238} \mathrm{U}$, wherein it would be possible to achieve criticality (over 1 imited concentration ranges). with a smaller quantity of ${ }^{235} U$ in the form of low enriched $U$ than if the ${ }^{235} U$ were in the highty enriched form

10. interacting finite cubic arrays of metal units wherein an unmoderated array of $30.0 \%{ }^{235} \mathrm{U}$ enriched spheres might have a lower critical lattice density, and hence ${ }^{235} \mathrm{U}$ mass, than an array of $93.2 \%{ }^{235} \mathrm{U}$ enriched spheres

11. effects of density changes in spherical cores with weakly absorbing reflectors (external moderation)

12. insertion of a neutron absorbing control rod into a Pu solution sphere wherein the effect of this was to cause the assembly's reactivity to initially increase as the rod entered the solution 
13. appearance of critically unbounded regions (of infinite masses) for slightly enriched uranium

14. criticality in the earth

15. criticality in the universe

16. an apparent chain reaction which took place in the Republique of Gabonaise some 100 million years ago with low $\left(3 \mathrm{wt} \%{ }^{235} \mathrm{U}\right)$ enriched uranium

17. criticality of even-n nuclides beginning with the naturally occurring element, ${ }_{91}^{231} \mathrm{~Pa}$

18. beyond Californiurn projection of the "micro" critical mass for the doublyclosed she11, super-heavy magic nuclei of the future

19. neutron multiplication and the power reactor (four billion watts and subcritical)

There can be as many as three different fuel concentrations with the same critical volume, and perhaps four different fuel concentrations may result in the same critical mass. Contrary to the usual expectation, the sphere, after all, may not be the configuration of least mass; the reflected cube may be somewhat less under certain circumstances. In some cases, the effect of added scatterers can significantly reduce the critical dimension; whereas, in others the result can be precisely the opposite.

Reducing core density can, under some circumstances, actually decrease the critical mass, contrary to the usual expectation that the mass will be increased. Surprising as it may seem, a system with $k_{\infty}<$ unity might be made critical by reducing the core size and adding a finite reflector of $\mathrm{D}_{2} \mathrm{O}$, etc., (in the latter case $\left.k_{\text {eff }}>k_{\infty} !\right)$. In some cases, the effect of moderation results in the smallest critical mass; whereas, in others (depending on the evenness or oddness of the nuclide), the effect is again precisely the opposite.

It is noted that a homogeneous aqueous mixture of ${ }^{235} U$ and ${ }^{238} U$ could have a smaller ${ }^{235} \mathrm{U}$ critical mass (over a limited concentration range) with luw enriched. uranium than if the uranium were fully enriched $\left(93.5 \mathrm{wt} \%{ }^{235} \mathrm{U}\right)$, and that an. 
unmoderated interacting array of metal units (spheres of 30 wt\% $235 \mathrm{U}$ ) might have a lower critical density than an array of fully enriched uranium spheres, of identical volume, and thus a smaller critical ${ }^{235} \mathrm{U}$ mass in the array. There is an example wherein the effect of inserting a neutron absorbing rod into a Pu-solution-bearing sphere is to cause the reactivity to initially increase rather than decrease.

Pressures up to $10^{12} \mathrm{~atm}$, comparable with the pressure in the center of the sun, are now believed achievable with advanced giant lasers or electron beams which could change the density of a small pellet of fissionable material under irradiation by a factor of some 250, thus making it possible to achieve a supercritical event in a small pellet of Pu containing as little as $10^{-2} \mathrm{~g}$ Pu. One of the more interesting events in the annals of criticality is the discovery of an apparent prehistoric chain reaction (Nature's Anomaly) that took place in the Republique of Gabonaise some 100 million years ago with 3 wt\% ${ }^{235} \mathrm{U}$ enriched uranium.

Finally, it is interesting to recall that, in the presence of inherent neutron sources; even the power reactor will be technically subcritical ( $k_{\text {eff }}<1$ ) when operating in a constant power mode at any power level.

Still other anomalies are known. Several of the anomalies cited would constitute "autocatalytic reactions," for in the event of criticality, the reactivity would be increasingly enhanced as a consequence of the reaction. 


\section{AROMALIES OF CRITICALITY}

\section{A. INTRODUCTIOH}

A large body of knowledge has been accumulated on criticality, and the factors affecting criticality, since inception of the first chain reaction in 1942. (1-5) Criticality, however, is fraught with complexities, and, lest we become too complacent in the era of advancement, it may be well, at this time, to recount a few of the apparent anomalies - some of which have heretofore remained unpublished in the open literature.

The phenomenon of criticality depends on the interaction of neutrons with matter, and is characterized by a self-sustaining fission chain. reaction. Consider the conditions for achieving criticality. The exact configuration, or spatial density, for each kind of atom present in the system is relevant. Criticality, then, depends not only on the quantity of fissile material present, but on the size, shape, and material of any containment vessel which may be used, on the nature of any solvents or diluents, and on the presence of any adjacent material which may possibly return neutrons through scattering back into the fissile material. Most of the examples to be cited are not well known. Yet, without knowledge of these "anomalies" an unwise application of existing data could lead to potentialiy serious consequences. As an introduction to the apparent 'anomalies that follow, our discussion begins with a description of the variation between critical mass and radius as a function of concentration for plutonium spheres.

\section{B. COHPLEXITY OF CRITICALITY}

All factors which influence the interaction of neutrons with matter affect criticality. The following curves (Fig. 1), showing the complex 


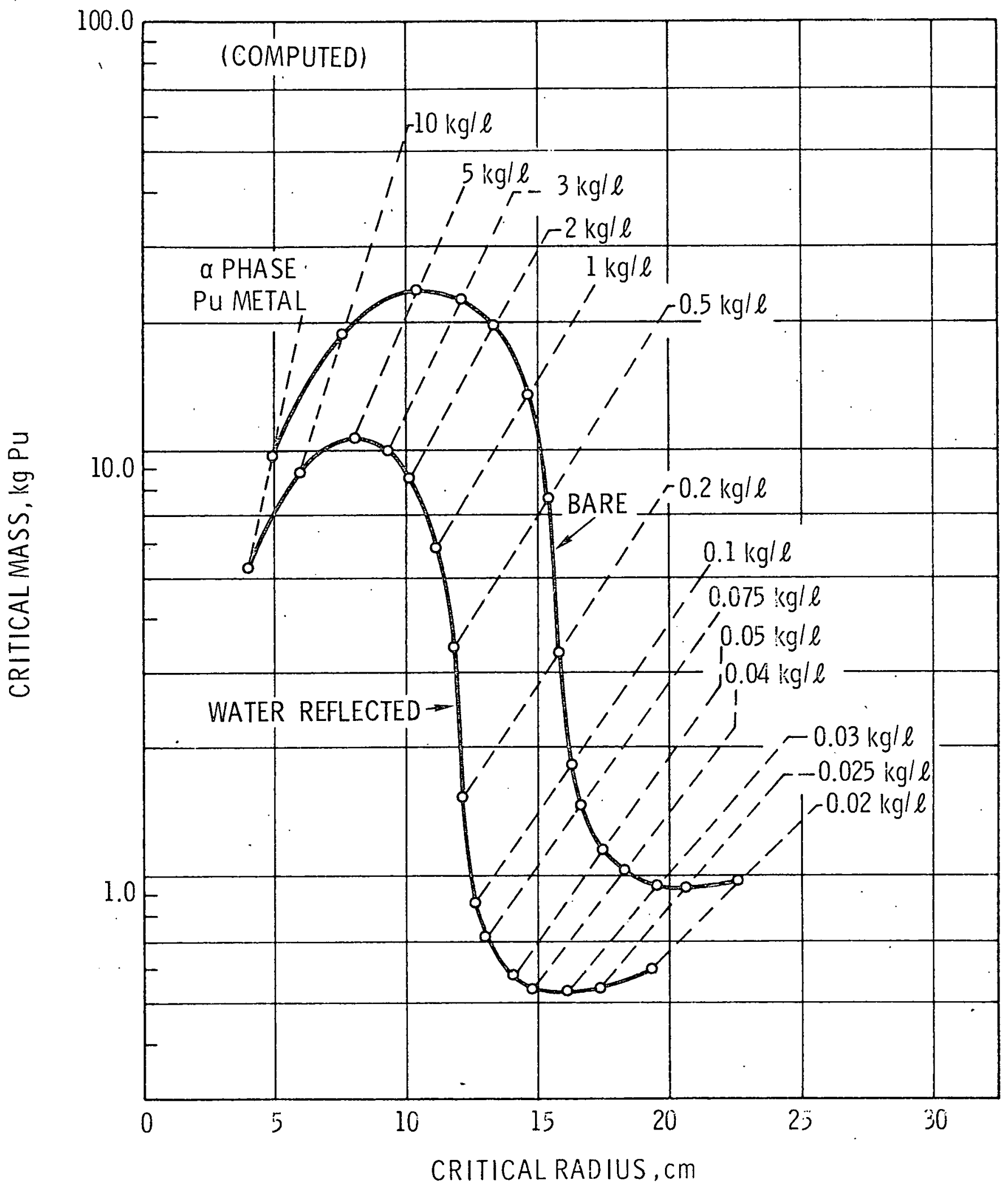

ESTIMATED MASS AND RADIUS OF CRITICAL PLUTONIUM -WATER SPHERES

FIGURE 1 . 
variation of critical mass with sphere radius for homogeneous ${ }^{239}$ Pu-water mixtures, serve to illustrate several effects. (6) The curves show critical radii of spheres, and critical masses of plutonium contained therein, as a function of water dilution. The upper curve is for bare, homogeneous plutonium-water spheres and the lower one for plutonium-water spheres immersed in water. Striking changes are seen to occur in the critical mass as the plutonium is diluted with water. Beginning with alpha-phase plutonium metal $\left(\rho=19.6 \mathrm{~g} / \mathrm{cm}^{3}\right)$, the critical mass and radius both increase on dilution with water. The mass passes through a maximum value at an $\mathrm{H} / \mathrm{Pu}$ ratio of about 4 (Pu density $\sim 5 \mathrm{~g} / \mathrm{cm}^{3}$ ).

The effect of partially moderating (or slowing down) the fission neutrons causes a significant reduction in the value of $n$ (number of neutrons produced per neutron absorbed in $\mathrm{Pu}$ ), due to the change in the ratio of the neutron capture and fission cross sections with neutron energy. In addition, the dilution of the metal with water also decreases $\ldots$ the density of Pu and increases the neutron leakage. The system must then be made larger to maintain a balance between production and losses of neutrons. On further dilution, moderation by the hydrogen in water becomes increasingly more effective and the probability for fissioning with slow neutrons is enhanced. The effect of adding water is seen to cause a further increase in leakage (and critical size), but the net overal1 result is a decrease in mass, due to the reduction in Pu density. Finally, on further dilution, or moderation, an optimum condition for production and leakage is obtained, such that the combination results in the smallest critical mass. At this point, the Pu concentration has been reduced to $32 \mathrm{~g} \mathrm{Pu} / \mathrm{H}(\mathrm{H} / \mathrm{Pu}$ atomic ratio $\sim 900)$. The critical solution volume is about 75 times larger than that for undiluted Pu metal, but the quantity of ru 
contained in the sphere is only about $1 / 10$ the metal value. This condition of "optimum moderation" gives a minimum critical mass for the waterreflected sphere that is $\sim 531 \mathrm{~g}$ Pu. (7) Finally, both the critical radius and mass increase once again on further dilution with water, due to increasing neutron absorption in the water (principally in the hydrogen). Both become infinite at a plutonium concentration of $7.2 \pm 0.1 \mathrm{~g} \mathrm{Pu} / \mathrm{l}$ ( $\mathrm{H} / \mathrm{Pu}$ ratio of $\sim 3680)$. (8) At this point, about half the neutrons released in fission are absorbed in the diluent.

Fig. 1 shows; also, the effect of neutron reflection. For the sphere immersed in water, some of the neutrons which would otherwise escape are reflected (scattered) back into the sphere, reducing the leakage. The curves show the difference in critical radii brought about by the water reflector.

Fig. 1 illustrates, also, that the same critical mass can be achieved with three different $\mathrm{Pu}$ concentrations, but that the critical volume or size will.differ in each case. Now, as criticality is approached, or as the size is increased, at any given concentration, $k_{\text {eff }}$ will increase and approach unity; $k_{e f f}$ is, therefore, an index of criticality. A pertinent question applicable to any system concerns the value of $k_{\text {eff }}$ for any given fraction of critical mass. In criticality safety analysis, it is common to evaluate safety in terms of a given value of $k_{\text {eff }}$; i.e., the system is safe providing $k_{\text {eff }}$ does not exceed 0.9 or 0.95 , etc. A problem arises because there is no general consistency between $k_{\text {eff }}$ and fraction of critical mass except at the point of criticality (where $k_{\text {eff }}=u n i t y$ ). Two different systems which have the same fraction of critical mass may have different values of $k_{\text {eff }}$. Stating it another way, for a specified value of $k_{\text {eff }}$ on two systems (with different fuel compositions), one system may have a higher fraction of critical 
mass and be "less safe" than the other. . This fact has perhaps not always been fully appreciated by those in the field.

The weird-complex variation in $k_{\text {eff }}$ of fraction of critical mass vs. critical mass is shown in Fig. 2 , where $k_{\text {eff }}$ has been computed by $R$. $D$. Carter, et a1., for two cases; $50 \%$ of a critical mass and $75 \%$, spanning the range of concentrations from Pu metal $(19.6 \mathrm{~g} \mathrm{Pu} / \mathrm{cc})$ to dilute aqueous solutions $(0.01 \mathrm{~g} \mathrm{Pu} / \mathrm{cc})$ for both unreflected and water-reflected systems.

\section{A Triple Point of Criticality}

Fig. 1 was used to illustrate some of the factors (such as moderation and reflection) that affect the criticality of systems containing a single actinide isotope (for purposes of illustration, $\left.{ }^{239} \mathrm{Pu}\right)$. The system becomes inherently more complex for mixtures of isotopes. The second most prevalent isotope of plutonium is ${ }^{240} \mathrm{Pu}$. The effect of the ${ }^{240} \mathrm{Pu}$ isotope on the criticality of ${ }^{239} \mathrm{Pu}-{ }^{240} \mathrm{Pu}$ mixtures is shown in Fig. $3 .{ }^{(9)}$ Calculations indicate that ${ }^{240} \mathrm{Pu}$ could, by itself, be made critical under certain conditions - specifically those under which there would be no moderation by a diluent. The interaction of a thermal neutron with ${ }^{240} \mathrm{Pu}$ results principally in scattering or the formation of ${ }^{24} \mathrm{Pu}$, since the fission cross section for slow neutrons is negligible. Thus, the effect of ${ }^{240} \mathrm{Pu}$ on the criticality of ${ }^{239} \mathrm{Pu}$ will be largely dependent on the neutron spectrum, which in turn is determined by the concentration and type of diluent present. The curves of Fig. 3 show the effect of $240 \mathrm{Pu}$ on the critical radius, and clearly indicate the existence of triple points of criticality. The effect is more clearly portrayed (schematically) in Fig. 4. 


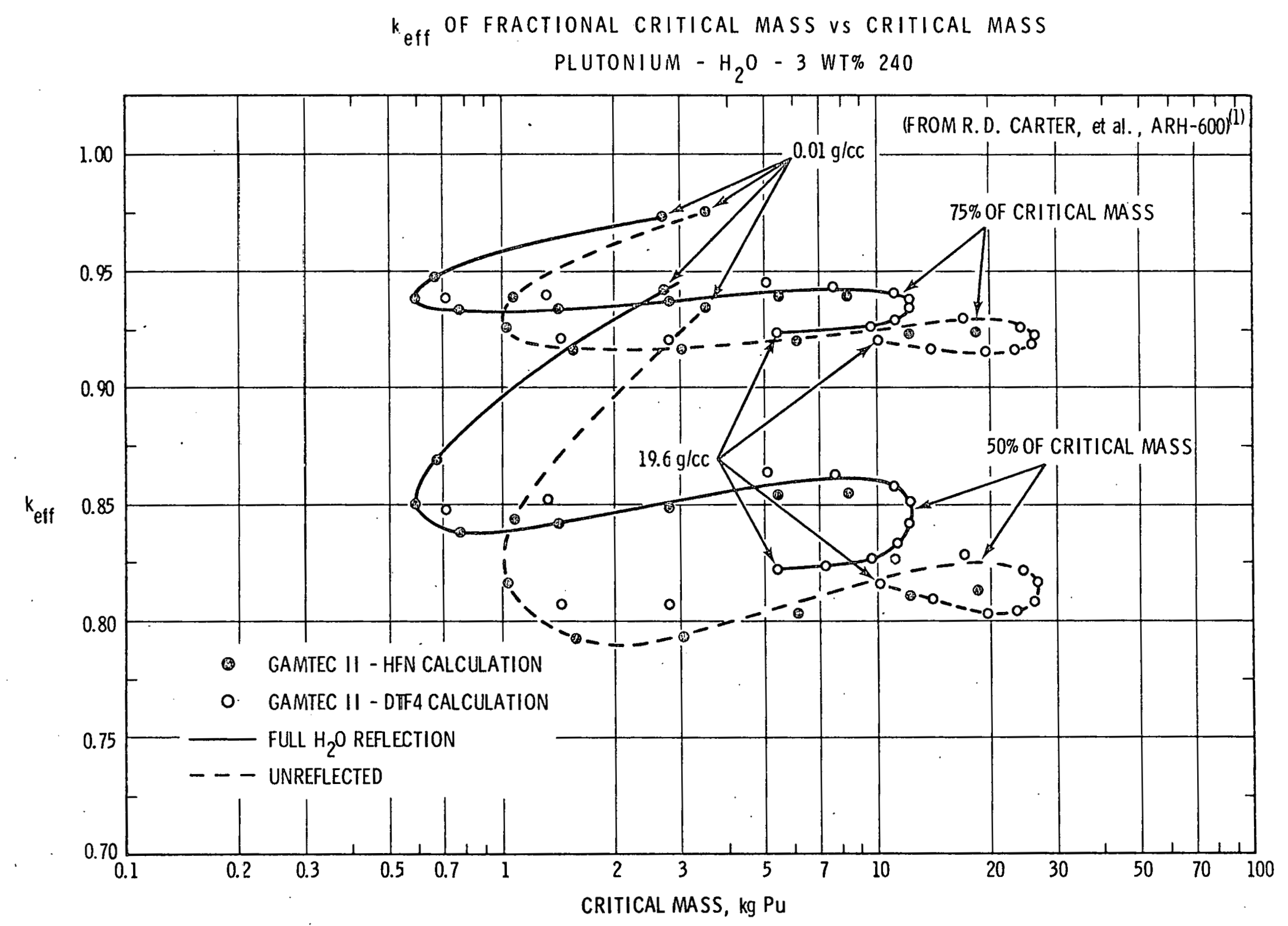

$\infty$ 
WATER REFLECTED SPHER ICAL CRITICAL RADII OF PU(METAL)-WATER MIXTURES

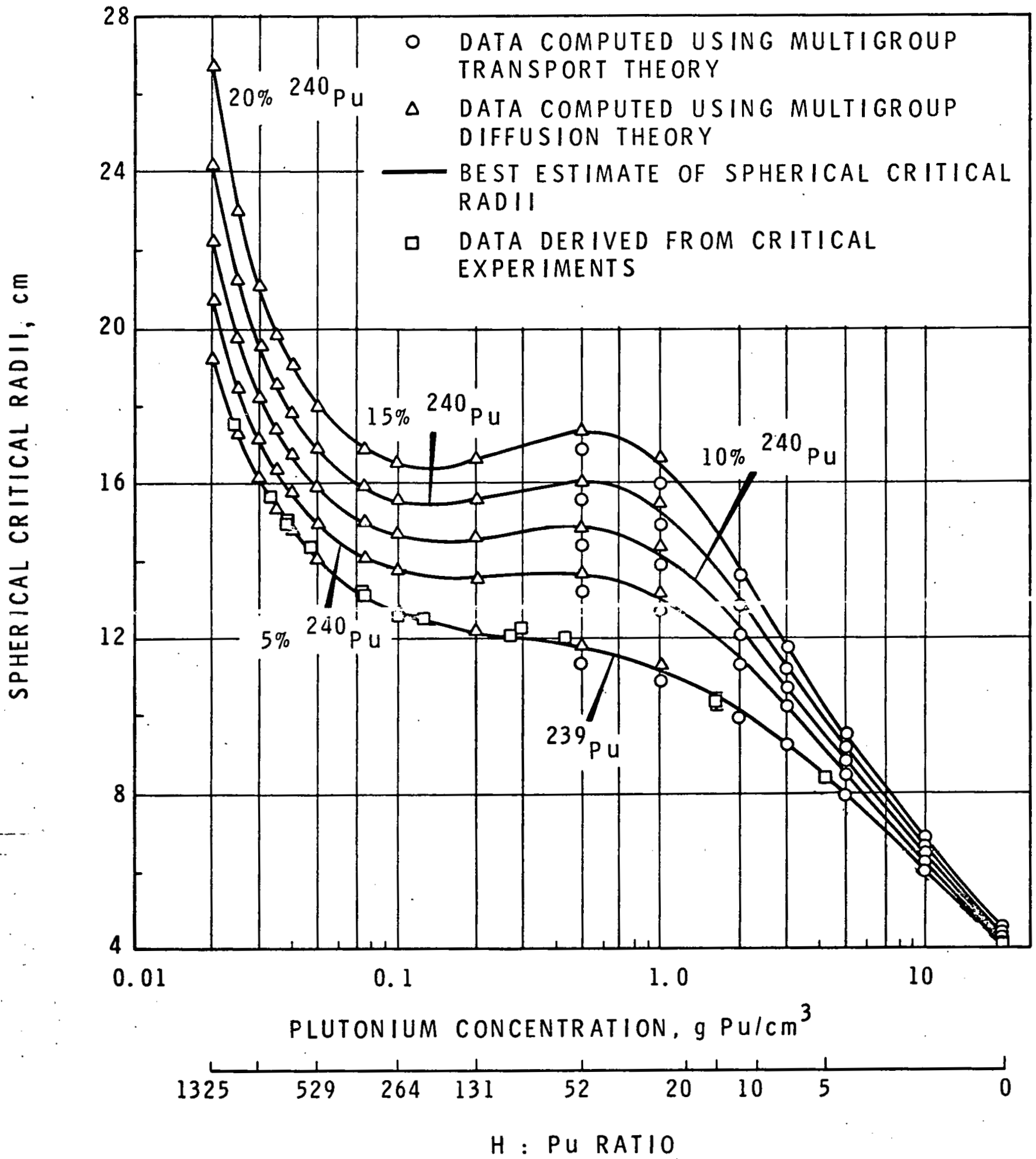

FIGURE 3 
SAME CRITICAL SIZE AT EACH OF THREE CRITICAL CONCENTRATIONS, a, b, c

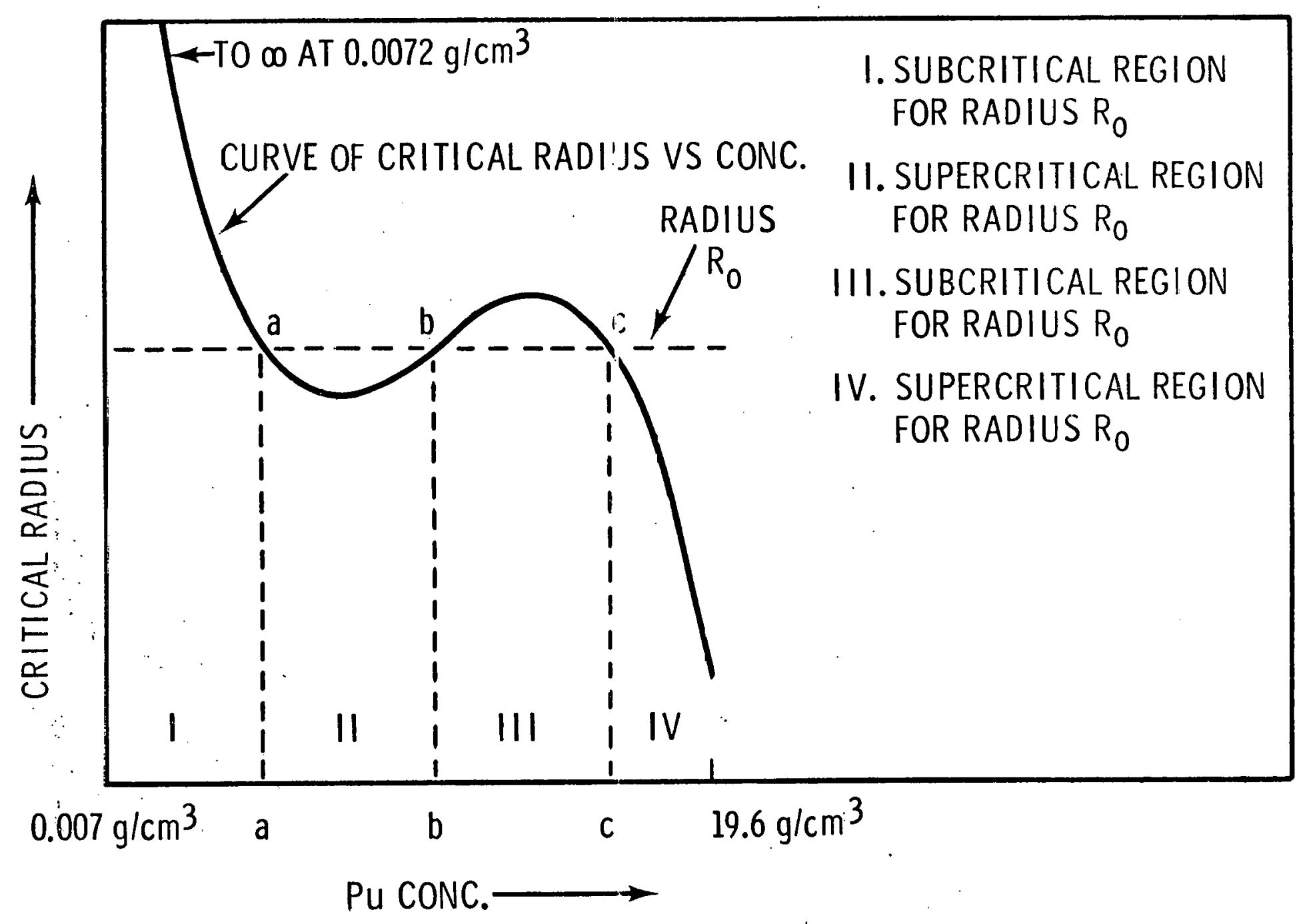

FIGURE 4 ; 
Note that for a given radius (or fixed volume) there may now be as many as three different critical concentrations! The system would then oscillate between regions that are subcritical and supercritical as a function of the fuel concentration. This is brought about by the mere addition or removal of fuel that changes the hydrogen-to-fuel ratio and, consequently, the neutron spectrum.

\section{One Mass and Four Concentrations}

Critical mass calculations are presented in Fig. 5 for mixed oxides of $U$ and $\mathrm{Pu}$ in which the Pu contains $25 \mathrm{wt} \%{ }^{240} \mathrm{Pu} .{ }^{(10)}$ If the peculiar curve shape at the higher concentration range is correct (note curves for 15 and $30 \mathrm{wt} \% \mathrm{Pu}$ in $U$ ) the results imply that it would be possible to achieve the same critical mass at four different concentrations of mixed oxides in water. In this case there would be four different volumes having the same critical mass, whereas, in the previous example (Fig. 4) there was one critical volume at three different fuel concentrations.

\section{THE CUBE AND THE SPHERE}

Since the ratio of surface area to volume is a minimum in the case of a sphere, and since neutron production depends on volume and neutron leakage on surface area, the sphere can be expected to have the smallest critical volume of any shape: There are data, however, that indicate that a reflected cube might, under some circumstances, have a smaller critical volume (and mass) than if the fissile material. were in the form of a sphere. This somewhat surprising result stems from experiments performed with $\mathrm{PuO}_{2}$-plastic compacts arranged in cubic geometry and reflected with Plexiglas. (11)(12) 
COMPUTED REFLECTED SPHERICAL CRITICAL MASS OF PUO ${ }_{2}^{-U O_{2}}$-WATER MIXTURES WITH 25 ISOTOPIC PERCENT ${ }^{240} \mathrm{PU}$

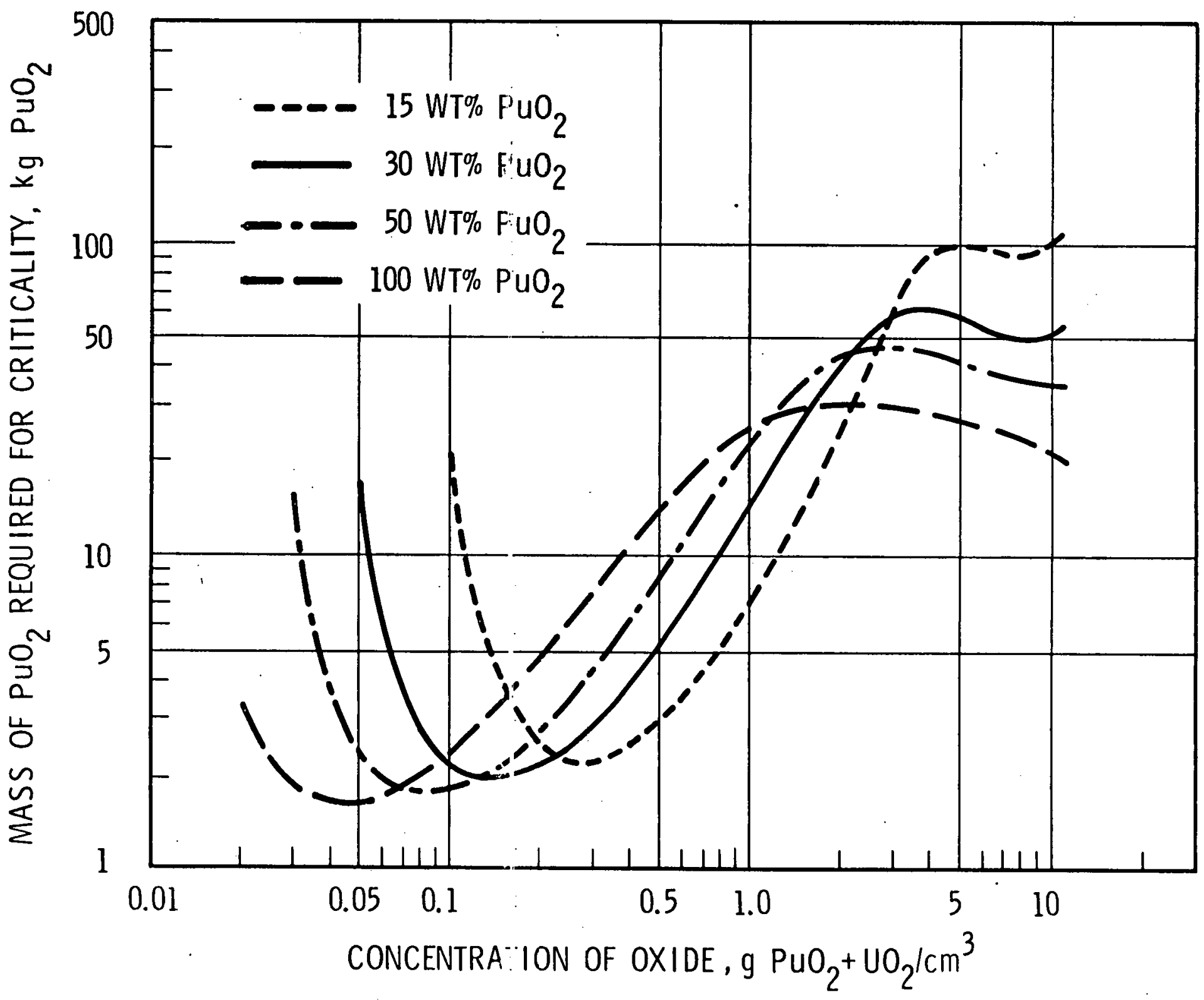


For $\mathrm{PuO}_{2}$ at an $\mathrm{H} / \mathrm{Pu}$ ratio of 0.04 (essentially unmoderated) the analysis indicates that a reflected cube would have a critical volume about $14 \%$ less than that for the reflected sphere. However, the phenomenon is not so pronounced that the apparent anomaly could not result from inaccuracies in the measurements. Monte Carlo calculations utilizing the KENO code $^{(13)}$ have since been made on a reflected cube and a reflected sphere of unmoderated $\mathrm{PuO}_{2}$ having precisely the same volumes; ${ }^{(14)}$ the results show the cube, in this case, to have a higher $k_{\text {eff }}$ (about $1 \%$ ) and tend to support the above, but the statistical uncertainty in the Monte Carlo calculations rules out firm conclusions. However, in examining data from a number of other experiments involving cubes of Pu-bearing fuels, it is to be noted that the effect (ratio of critical sphere volume to critical cube volume) is uniformly dependent on the $\mathrm{H} / \mathrm{Pu}$ ratio, or degree of moderation, as is evident from Fig. 6. In the case of well moderated (and larger systems) the reflected sphere does, as expected, have a critical volume or mass about $20 \%$ less than that of the reflected cube, and the Monte Carlo calculations are in support of these results. It also has been concluded that for some undermoderated mixtures of $U(93.5 \%$ enriched) and water, a right circular cylinder with height-to-diameter ratio $(h / d)$ of about 0.9 may have a slightly smaller water-reflected critical volume than a sphere. $(1)(15)$ This same effect also was reported to have been seen in the results of some two dimensional neutron transport calculations made by G. E. Hansen. (15) These conclusions lend additional support to our conclusions regarding the cube and the sphere. In passing, it may be of interest to note that, in practice, materials are more likely to be encountered in the form of rectangular parallelepipeds or cylinders than in the form of spheres. 


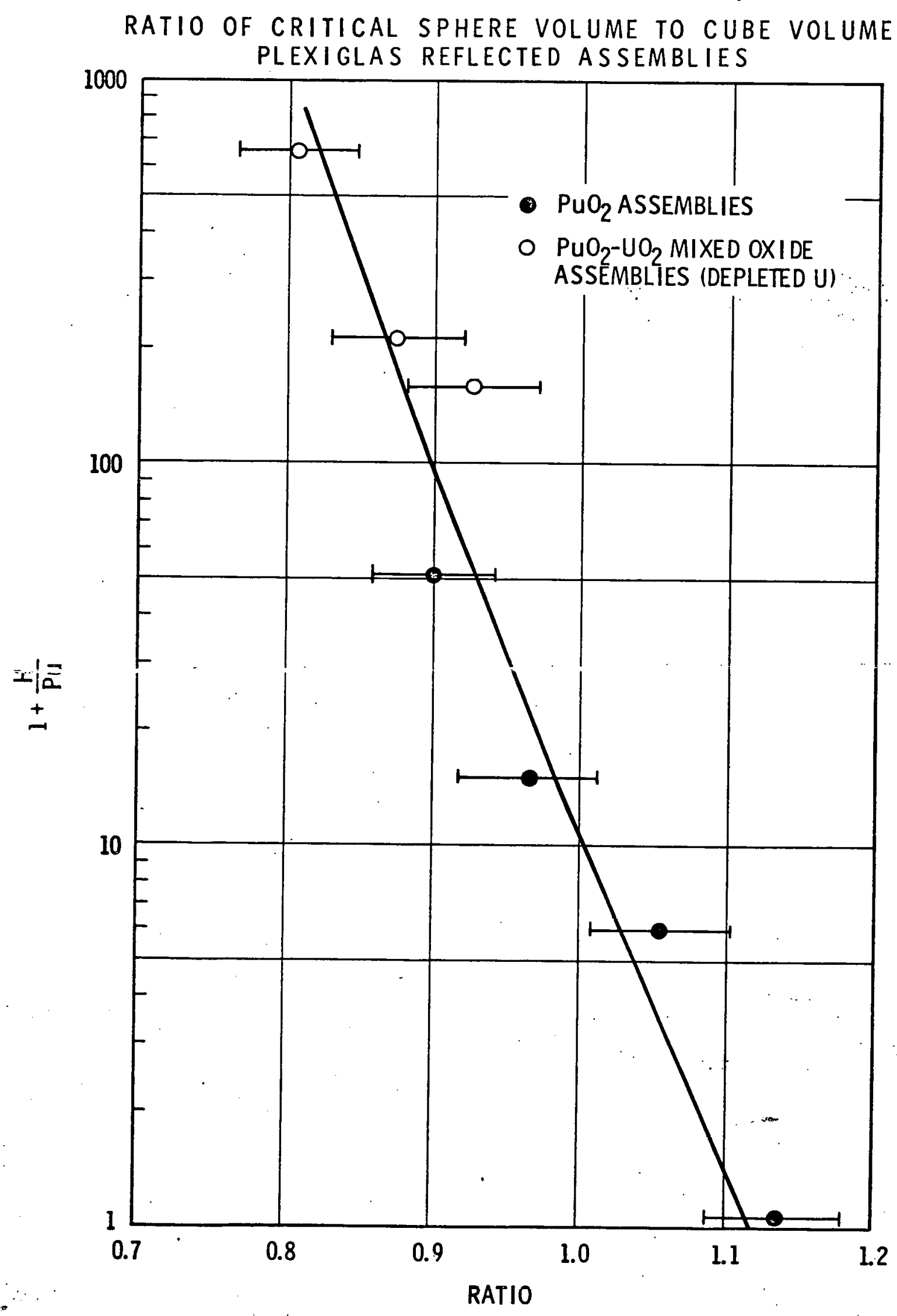

FIGURE 6 


\section{ADDED SCATTERERS AND MODERATION}

In Fig. 1 and 3, the critical mass and radius for various plutonium concentrations were seen to vary continuously, in a smooth but somewhat complex manner. We shall now consider the effect of adding water to the fissile core without at first changing the density of the fissile isotope.

1. A Point of Discontinuity

Fig. 7 shows the effect of adding water to mixed oxides of $\mathrm{Pu}$ and $\mathrm{U}$ beginning at $7 \mathrm{~g} / \mathrm{cm}^{3}$ in water plotted as a function of the fractional weight of water added. (16) The sphere volume is seen to decrease initially as the water fills the void space in the oxides. A point of discontinuity occurs at saturation in the example given. Beyond this point the further addition of water reduces the density of the mixed oxides and the criti-

- cal volume is seen to increase. The result is that the critical volume changes abruptly from a decreasing to an increasing function.

The curve shape is the result of four effects: added scatterers which initially reduce neutron leakage, moderation by hydrogen, the change in density of mixed oxides, and, finally, excess neutron absorption in hydrogen becomes predominant.

2. The Reduction in Mass nf the Sphere

The next example (Fig. 8) serves to illustrate the large reduction in critical mass that can be brought about by the mere addition of water to oxide at reduced density. (16) The straight lines show the increase in mass as a result of reducing the density of the mixed oxides. The bottom curves give the critical masses for saturated oxides. Note that critical mass reductions of about 200 are theoretically possible on simple saturation of the reduced density oxides with water. 
COMPUTED CRITICAL VOLUME AS WATER IS ADDED TO $30 / 70 \mathrm{PuO}_{2} /{ }^{235} \mathrm{UO}_{2}$ AT $7 \mathrm{~g} / \mathrm{cm}^{3}$

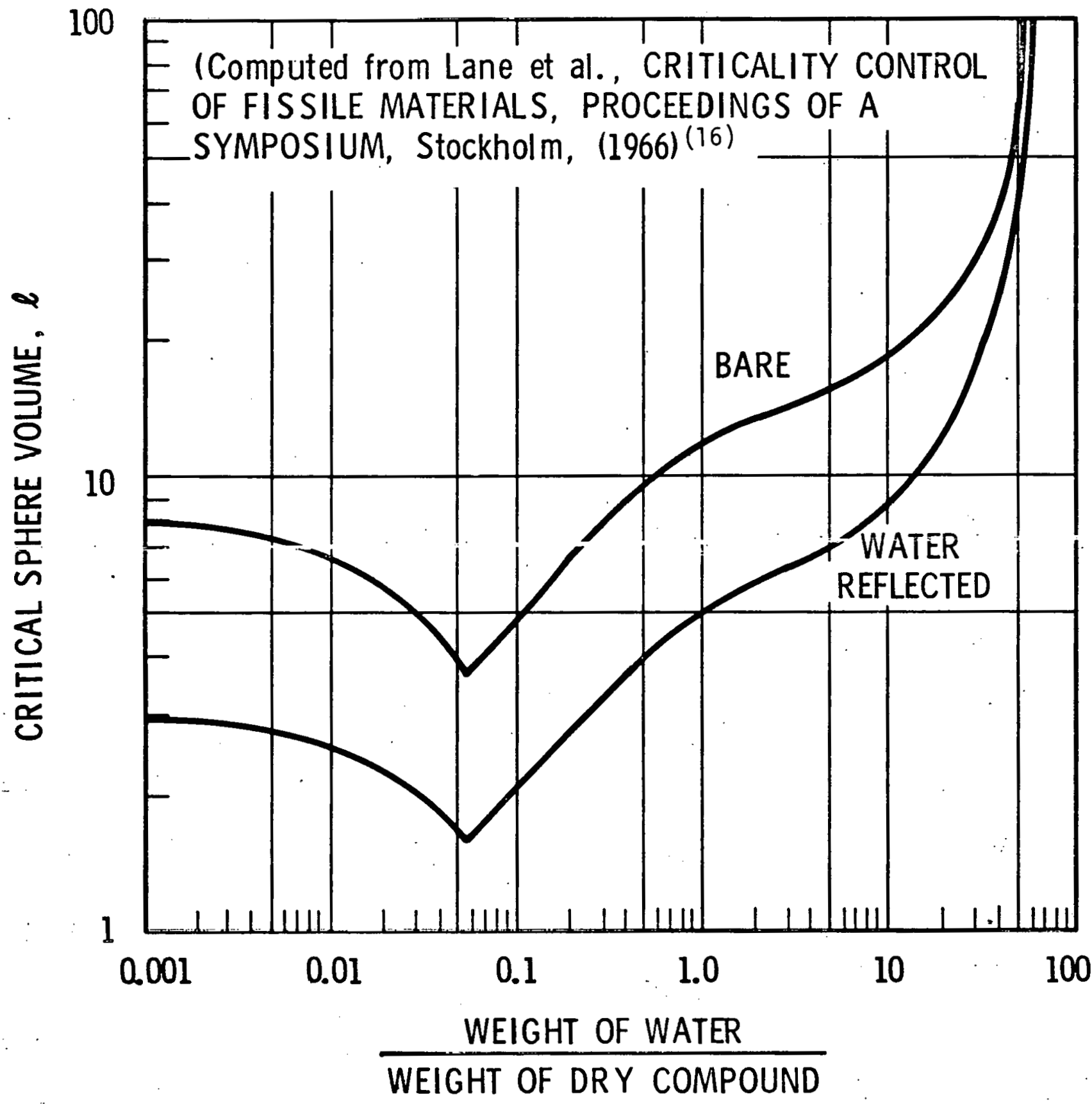

FIGURE 7 
COMPUTED MASSIVOLUME CURVES

FOR $30 / 70 \mathrm{PuO}_{2} /{ }^{235} \mathrm{UO}_{2}$

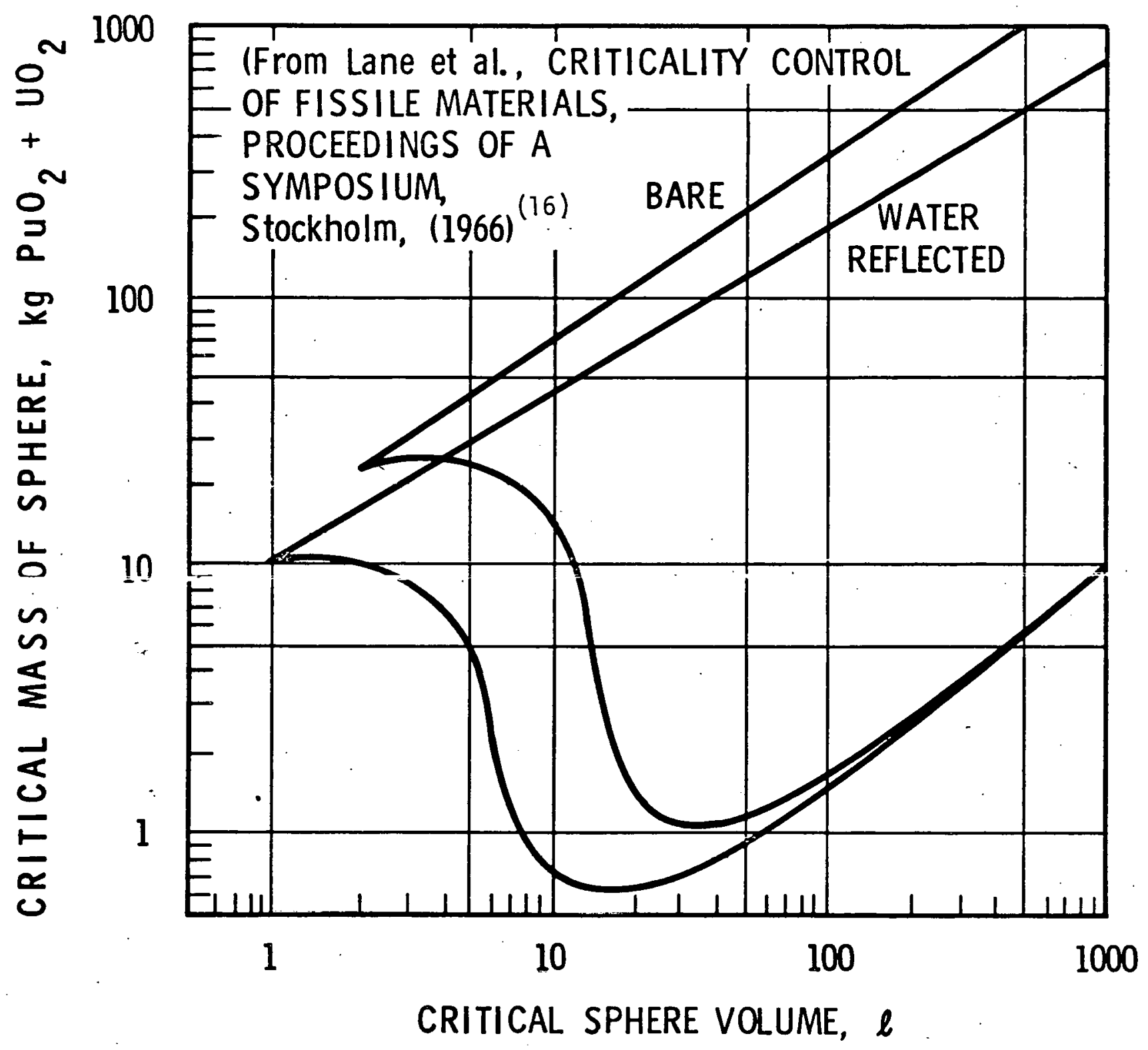

F.IGURE 8 
3. The Paradox of the Infinite Slab

The following example is interesting because it demonstrates that, under some circumstances, the effects will be directly opposite to those illustrated in the previous examples; not only will there be no reduction in critical mass with added scatterers, but the critical size can actually be increased.

The effect of added scatterers on the criticality of slabs was first reported by $E$. R. Woodcock in $1961^{(17)}$ and later studied in detail by Makoto Iwai. (18)

E. R. Woodcock had reported that, if the core were in the form of a thin disc or slab, a reverse effect could occur in which the additional scattering centers would now tend to scatter neutrons out of the core and the critical size would increase.

Makoto Iwai performed a study on the effect of added scatterers $(0, C, N)$ on criticality by means of transport theory calculations utilizing the DTF-IV code. ${ }^{(19)}$ His study pertained to plutonium compounds likely to be encountered throughout the nuclear industry - in fuel processing and fabrication processes. His results do, indeed, confirm that, in some cases of unmoderated thin slabs with hydrogenous reflectors, the effect of added scatterers can cause an increase in the critical dimension contrary to the usual expectation that the size should be reduced in such cases. The dominant factor causing the increase in slab thickness was the decrease of neutron leakage into the moderating reflector. 


\section{E. DENSITY EFFECTS}

The variation of critical size and mass with changes in density is of special interest. For a bare system to remain critical, while the density is changed uniformly, all the linear dimensions must be scaled inversely as the density. To maintain the same nonleakage probability or the same number of mean free paths in the system, the dimensions and density must be inversely proportional. It follows that the critical mass of an unreflected sphere will vary inversely as the square of the density, $M_{c} \sim \rho^{-2}$. For infinitely long cylinders, the critical mass per unit length will vary inversely with density, $M_{C} \sim \rho^{-1}$. In the case of infinite slabs, the mass per unit area, $M_{c}=\rho^{0}=$ constant, and remains unchanged. An unreflected infinite slab which is subcritical remains so, irrespective of the density; criticality in this case could be achieved only by adding more material to the slab so as to increase the mass per unit area. For reflected systems, in which the core and reflector density are varied independently, the variation in the critical mass for finite geometries is given by

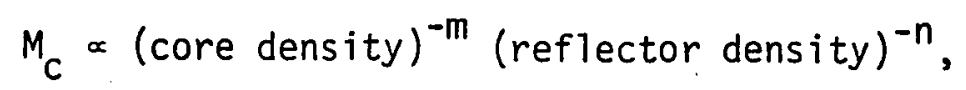

with the provision that $m+n=2$ (20) $^{(20)}$

We shall now cite an example contrary to the usual expectation that the critical mass should be increased as the core density is reduced.

1. External Moderation

Surrounding the fissile material with thick moderating and weakly absorbing reflectors such as graphite, heavy water, or beryllium, can cause striking and unexpected changes to occur with core density change. (15)(21) The effect is illustrated in Fig. 9, where the critical mass of U(93.5) metal reflected by graphite and beryllium has been plotted against density of 
COMPUTED CRITICAL MASSES OF U (93.5) METAL REFLECTED BY THICK GRAPHITE OR BERYLLIUM FOR A WIDE RANGE OF $235 \mathrm{U}$ DENSITIES

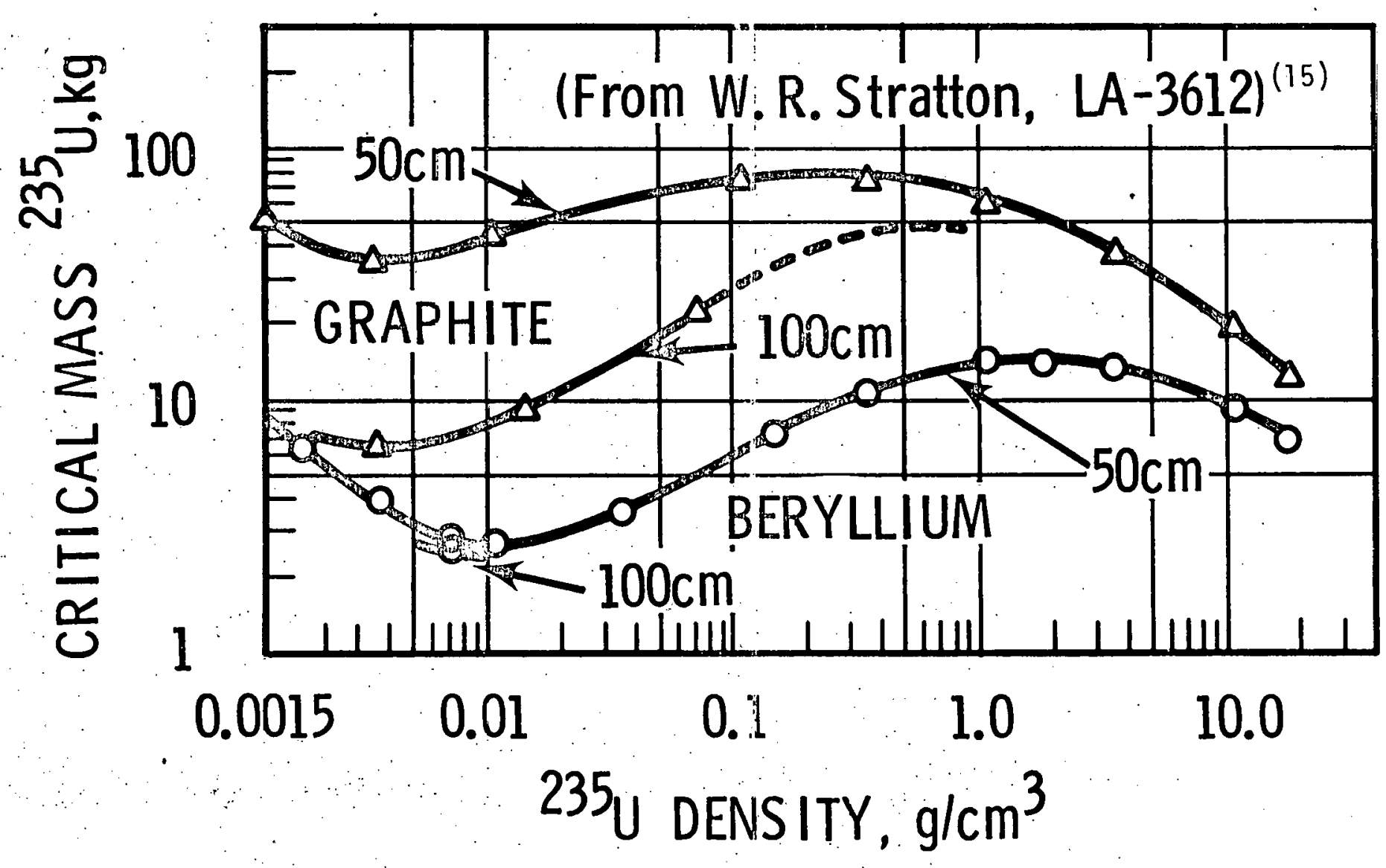


${ }^{235} \mathrm{U}$ metal in the core. The critical mass is, at first, seen to increase, and then, contrary to the usual expectation, the change reverses itself and the critical mass decreases with decreasing core density. It should be borne in mind that the core is not being diluted with any material, but merely reduced in density.

The region of core density throughout which a decrease causes a smaller critical mass would be critically unstable with respect to an increase in temperature. In the event of criticality, the heat from fission would reduce the core density and cause a further increase in reactivity. This autocatalytic process would then continue until the core density was sufficiently low that the critical mass was again increasing as the core density was reduced, or until the reflector was reduced in density sufficiently to reduce its effectiveness.

2. Internal Moderation - Unbounded Regions and Multiple Infinity

As interesting as the preceding example may be, the following anomaly is perhaps even more strange. The variation in critical mass with core density change for a weakly absorbing reflector (such as graphite) was shown in Fig. 9. It should be borne in mind that this variation was merely the result of a simple density change within the core. Let us now consider the combined effects of reducing the core density and also filling the void space with graphite (diluting the core with graphite). For this particular illustration there will be no external reflector; the core will be unreflected, or bare, but internally moderated.

A parametric study was made in 1967 by L. B. Engle and W. R. Stratton (22) of bare homogeneous spheres containing ${ }^{235} \mathrm{U},{ }^{238} \mathrm{U}$ and carbon in various mixtures. Figure 10 shows the unusual results of their calculations. There is 
CRITICAL MASS (kg 235 U) OF HOMOGENEOUS SPHERES CONTAINING ${ }^{235} \mathrm{U},{ }^{238} \mathrm{U}$ AND CARBON VS ${ }^{235} \mathrm{U}$ DENSITY FOR VARIOUS ${ }^{235}$ U ENRICHMENTS

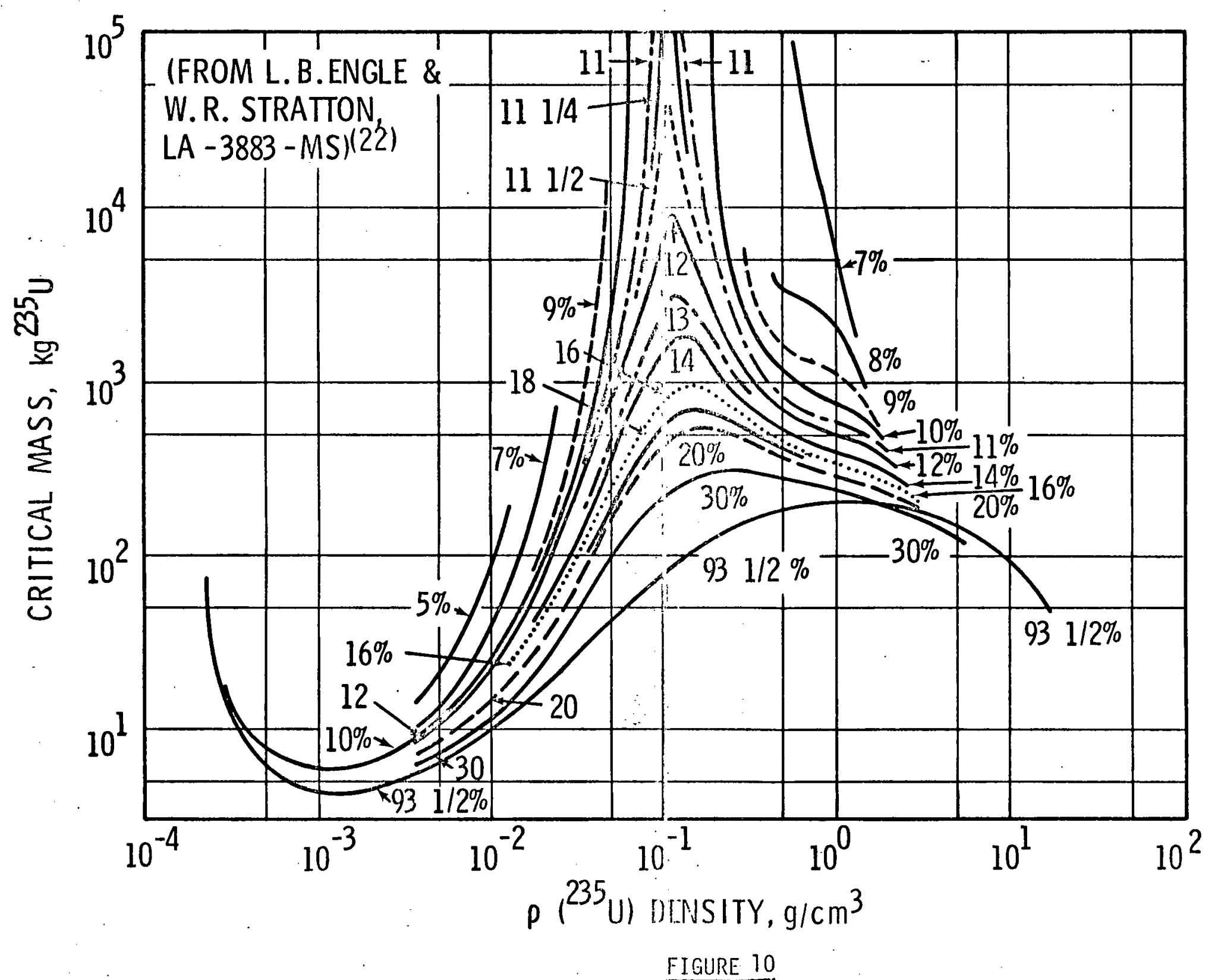


nothing unusual about the curve for fully enriched uranium (93-1/2\%), but note the appearance of critically unbounded regions for ${ }^{235} U$ densities between about $10^{-2}$ and $2 \mathrm{~g} / \mathrm{cc}$ for uranium enrichments less than $\sim 11 \%$. It is also true that, for every enrichment, the critical mass will become infinite on the left side of the Fig.; i.e., for sufficiently small ${ }^{235} \mathrm{U}$ densities (at large $C /{ }^{235} \mathrm{U}$ ratios). The minimum critical enrichment for metal (enrichment for which $k_{\infty}$ is unity with no dilution) was computed to be $5.694 \%$. (22) Now it is clear that whenever $k_{\infty}$ becomes unity the critical mass becomes infinite.

The calculations show the critical mass to become infinite at three different ${ }^{235} U$ densities, providing the enrichment is in the range between 5.7 and $17 \%$. This can be explained as follows. As carbon is added to the metal, the neutron spectrum will be degraded slightly in energy. Eta for ${ }^{235} \mathrm{U}$ will be reduced somewhat, as will fast fission in ${ }^{238} \mathrm{U}$; to the contrary, rocnnance cantura in $238_{\mathrm{u}}$ wi 111 be solrievilat ennanced. Over a range of c/U ratios $k_{\infty}$ will become, and remain, less than unity; but on further moderation, as the neutron spectrum becomes sufficiently well thermalized, resonance capture in $238 \mathrm{U}$ will be significantly reduced and $k_{\infty}$ will now exceed unity. Ultimately, excessive absorption in the graphite (at very low ${ }^{235} \mathrm{U}$ densities) reduces $k_{\infty}$ to values that are again less than unity. Thus, within the enrichment ranges defined, there can be as many as three different $C /{ }^{235} U$ atom ratios for which $k_{\infty}$ is unity and the critical masses and dimensions become infinite.

\section{F. CRITICALITY AND THE NEGATIVE BUCKLING CORE}

The example under "External Moderation" served to illustrate that, under certain circumstances, the critical mass could be reduced by a reduction in core density, but for the cases described, $k_{\infty}$ (the reproduction factor for an infinite size core) would always have exceeded unity. We shall now cite an example that is 
contrary to the usual expectation that $k_{\infty}$ for the fuel mixture has to be greater than unity if criticality is to be achieved. It follows logically from the simple formula, $k_{\text {eff }}=k_{\infty} P$, where $P$ is the nonleakage probability, that $k_{\text {eff }}$ becomes equal to ko for the case of no neutron leakage (an infinitely large system).

It would be reasonable to assume, therefore, that, if the system could be made infinitely large and remain subcritical, a reduction in size could hardly be cause for concern. Yet, an example can be given in which $k_{\infty}$ of the core is less than unity (the core buckling is negative), but criticality can be achieved nonetheless.

In 1968, a study was made of the possibility of inducing criticality in unmoderated, negative buckling cores of slightly enriched uranium by using moderating reflectors. (23) It was demonstrated (by means of calculations) that, given certain reflector conditions, a finite, reflected system with negative core buckling $\left(k_{\infty} \leq 1.0\right)$ could have a $k_{\text {eff }} \geq 1.0$. Some of $M$. $L$. Blumeyer's results are included in the following table, which illustrates the point in question and shows $k_{\text {eff }}$ to be greater than $k_{\infty}$.

\section{TABLE 1}

\begin{tabular}{|c|c|c|c|c|}
\hline \multicolumn{5}{|c|}{$\begin{array}{c}\text { Cumpuled } k_{\text {eff for Spheres of } 1000 \mathrm{~cm} \text { Corc Radius }} \\
\text { with } 500 \mathrm{~cm} \text { Thick } \mathrm{D}_{2} 0 \text { Reflector }\end{array}$} \\
\hline Material & Enrichment & $\mathrm{H} / \mathrm{U}$ in Core & $\underline{k_{\infty}}$ & $\underline{k}$ eff \\
\hline $\mathrm{UO}_{2}$ & $3.10 w t \%$ & 0.59 & 0.999 & 1.109 \\
\hline $\begin{array}{l}\text { Urany1 Nitrate } \\
\qquad \mathrm{UO}_{2}\left(\mathrm{NO}_{3}\right)_{2}\end{array}$ & 2.26 wt $\%$ & 5.90 & 0.999 & 1.012 \\
\hline $\begin{array}{l}\text { Metal - Full } \\
\text { Density }\end{array}$ & $2.96 w t \%$ & zero & 1.006 & 1.170 \\
\hline
\end{tabular}


The results for 1 ight water reflectors were inconclusive, but negative for the few cases examined. It, therefore, remains problematical as to whether a system with a negative buckling $\left(k_{\infty}<1\right)$ could be found that could be made supercritical in finite size with light water reflection.

\section{G. THE COMPLEX REFLECTOR}

The critical mass, or dimension, is reduced as a result of neutron reflection from materials external to the fissile bearing core. There are wide differences in the effectiveness of reflectors, but in a relative sense, the best reflector is that which results in the smallest critical size. Reflectors frequently consist of more than one layer of reflecting material such as steel and water or steel and concrete, etc. Although it might appear logical to assume that a combination of reflecting layers would not be better than the best reflector separately, there are noted exceptions :

Experiments with a ${ }^{2} 35 \mathrm{UH}_{3} \mathrm{C}$ sphere, reflected with layers of nickel and natural uranium, show a composite reflector consisting of $1 / 2$ in. thick nickel next to the core, surrounded by natural uranium, gives a significantly smaller critical mass than either reflector alone. (24)

There is no verified explanation for the effect, but it is suspected that it may be associated with a strong scattering resonance that nickel has at about $16 \mathrm{keV}$.

\section{H. THE DISSOLVER PARADOX}

The dissolution process can involve fissile material in the form of metal or oxide initially; whereas, during the intermediate stage, the material will be surrounded by a solution containing the partially dissolved material. In the final step, all of the material is dissolved, with the concentration being determined by the quantity of material starting the process. 
One might conciude that if the material were subcritical initially, and when fully dissolved, the process could safely proceed, but this does not necessarily follow, as during the intermediate stage of the coupled fast-thermal system, criticality may occur.

In the case of an idealized plutonium dissolver, it has been shown that, at least for the conditions. assumed, it is possible to begin dissolution in a system that is subcritical at both the starting and ending configurations and yet achieve supercriticality somewhere in between al though the total mass of $\mathrm{Pu}$ in the form of solution and/or in metal or oxide has remained constant (see illustration, Fig. 11.) (26)

The computed curves in Fig. 12 show the critical masses (total Pu-239 in metal and sphere solution) and the corresponding critical volumes of the dissolver (regions I and II). The critical envelope is drawn tangentially to the various curves and the subcritical region is the region below this envelope. The possibility ef a system boing subcritica? at the bcgimining unin eind of dissolution, yet being supercritical. in between is further illustrated in Fig. 13 for the case of a 3-kg mass dissolving into a 5-1iter volume. The critical mass becomes less than $3 \mathrm{~kg}$ total mass at or near $40 \mathrm{~g} / 1 \mathrm{iter}$ in solution and reaches a minimum of $2.8 \mathrm{~kg}$ at about $100 \mathrm{~g} / \mathrm{liter}$. In the example given the system would then have become supercritical at a solution concentration $>40$ g/liter and would have remained so until the concentration reached about 350 g/liter.

I. $235 \mathrm{U}-238 \mathrm{U}$ MIXTURES (CONCENTRATION OR MODERATION - EFFECT ON CRITICAL MASS)

At first hand, it may seem surprising that, in the case of a homogeneous aqueous mixture of low enriched uranium, the ${ }^{235} \mathrm{U}$ mass required for criticality can be significantly less than for fully enriched $U(93.5 \%)$ within a narrow $H / U$ range at the same total $\left({ }^{235} U+{ }^{238} U\right)$ concentration. (27) This is evident from Figure 14 , which gives computed ${ }^{235} U$ critical masses for 5.0 wt\% 
PU METAL DISSOLUTION
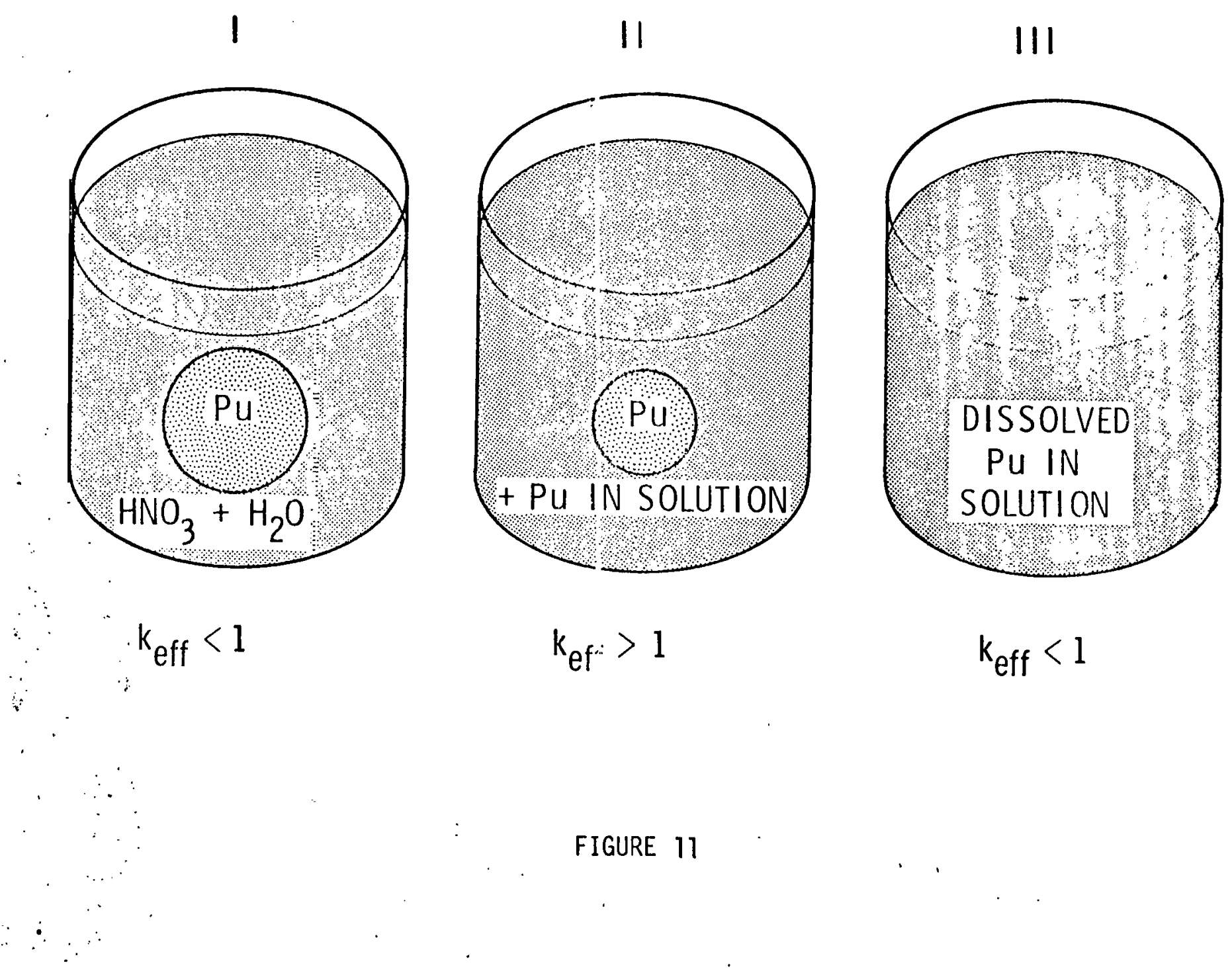


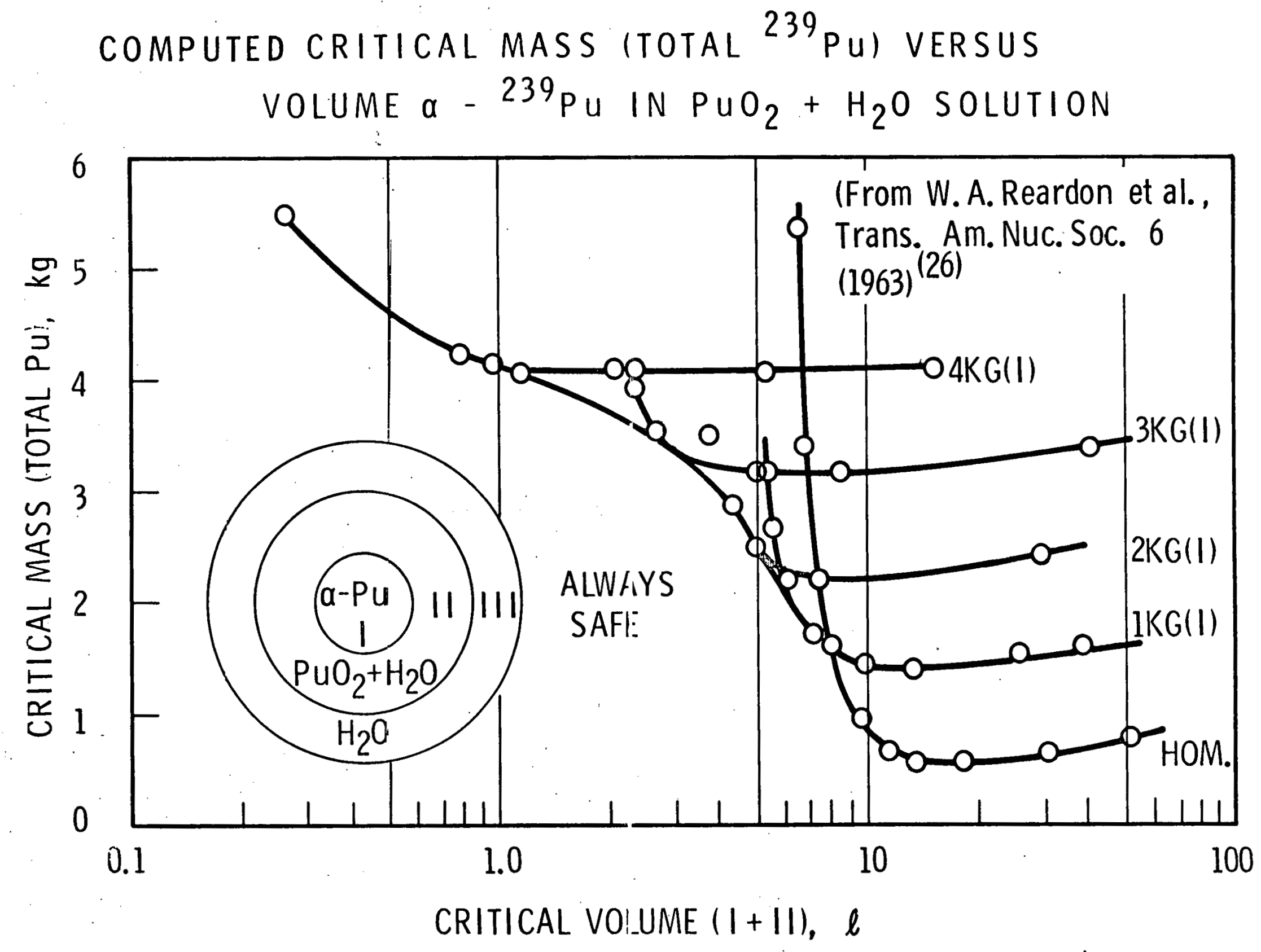

FIGUI,ZE 12 
COMPUTED CRITICAL MASS VERSUS SOLUTION CONCENTRATION;

$3 \mathrm{~kg}$ DISSOLVING INTO 5 LITER VOLUME

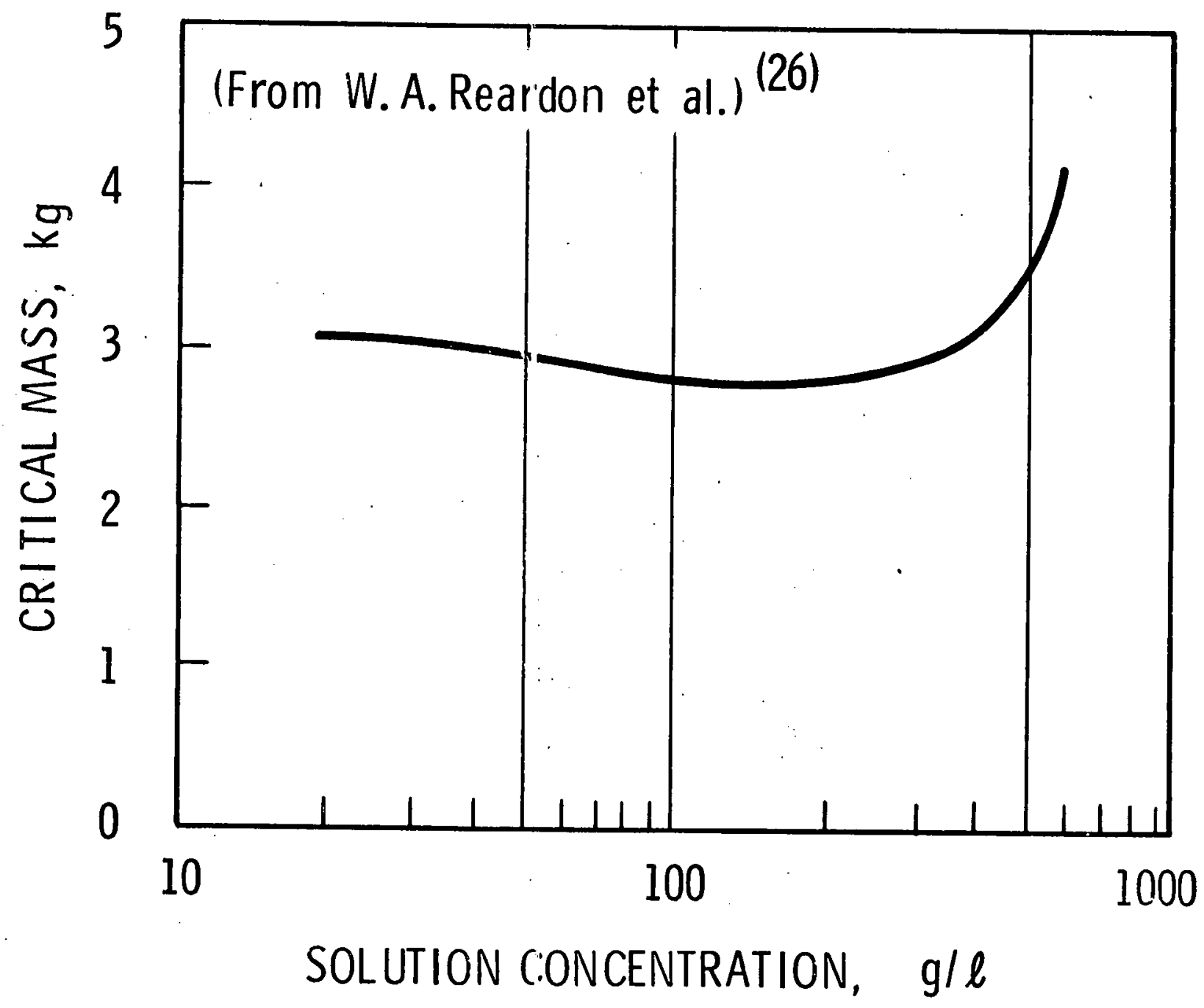




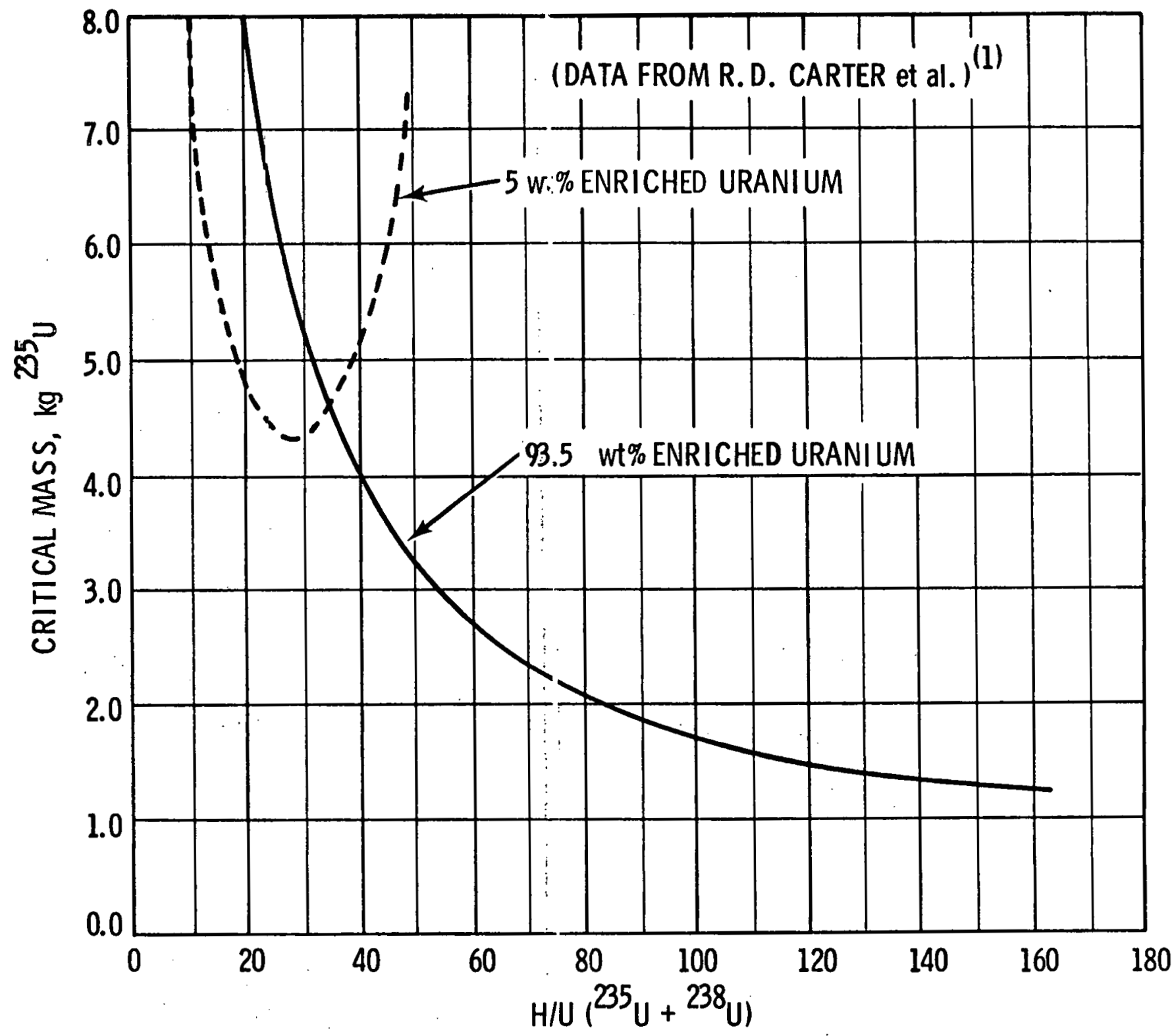

COMPUTED CRITICAL MASSES OF WATER REFLECTED SPHERES OF URANYL NITRATE SOLUTIONS (NO EXCESS $\mathrm{HNO}_{3}$ ) 
enriched $U$ and $93.5 w t \% U$ plotted against $H / U(235 U+238 U)$ atom ratios. However, in cases such as these, it is always the $H /{ }^{235} \mathrm{U}$ ratio, rather than concentration per se, that is the controlling factor. If both curves were plotted against $\mathrm{H} /{ }^{235} \mathrm{U}$ ratio (instead of total $U$ ), the lower enriched uranium case would be seen to have the larger ${ }^{235} \mathrm{U}$ critical mass for the same $\mathrm{H} /{ }^{235} \mathrm{U}$ ratio.

It should be borne in mind, however, that in nongeometrically safe situations (wherein vessels are not safe by geometry) it would be possible to achieve criticality (albeit over limited concentration ranges) with a smaller quantity of ${ }^{235} U$ in the form of low enriched $U$ than if the ${ }^{235} U$ were in the highly enriched form:

Not, however, explained are some interesting calculations that indicate an interacting array of $30.0 \%{ }^{235} \mathrm{U}$ enriched metal spheres could have a lower critical lattice density than an array of $93.2 \%{ }^{235} \mathrm{U}$ enriched spheres,. of identical volume, and thus a smaller critical ${ }^{235} \mathrm{U}$ mass in the lower enrichment array. (28) (See Figure 15.) In the case of these interacting arrays, the calculations imply that a situation might be obtained whereby a smaller critical ${ }^{235} \mathrm{U}$ mass could be achieved in a given array volume by mixing the ${ }^{235} \mathrm{U}$ with ${ }^{238} \mathrm{U}$ ! The array would contain fewer, but larger, units distributed over its volume with a net reduction in total ${ }^{235} U$ content.

\section{J.. AN ARRAY ANOMALY}

1. Mixed Units in Storage

The criticality of an array of units involves the effect of neutron interaction between like or dissimilar quantities of other nuclear materials that may be in the vicinity. Suffice it to say, the problem of computing criticality becomes more complex when interacting arrays of units are to be considered, such as may occur in storage areas and in shipments of containers 


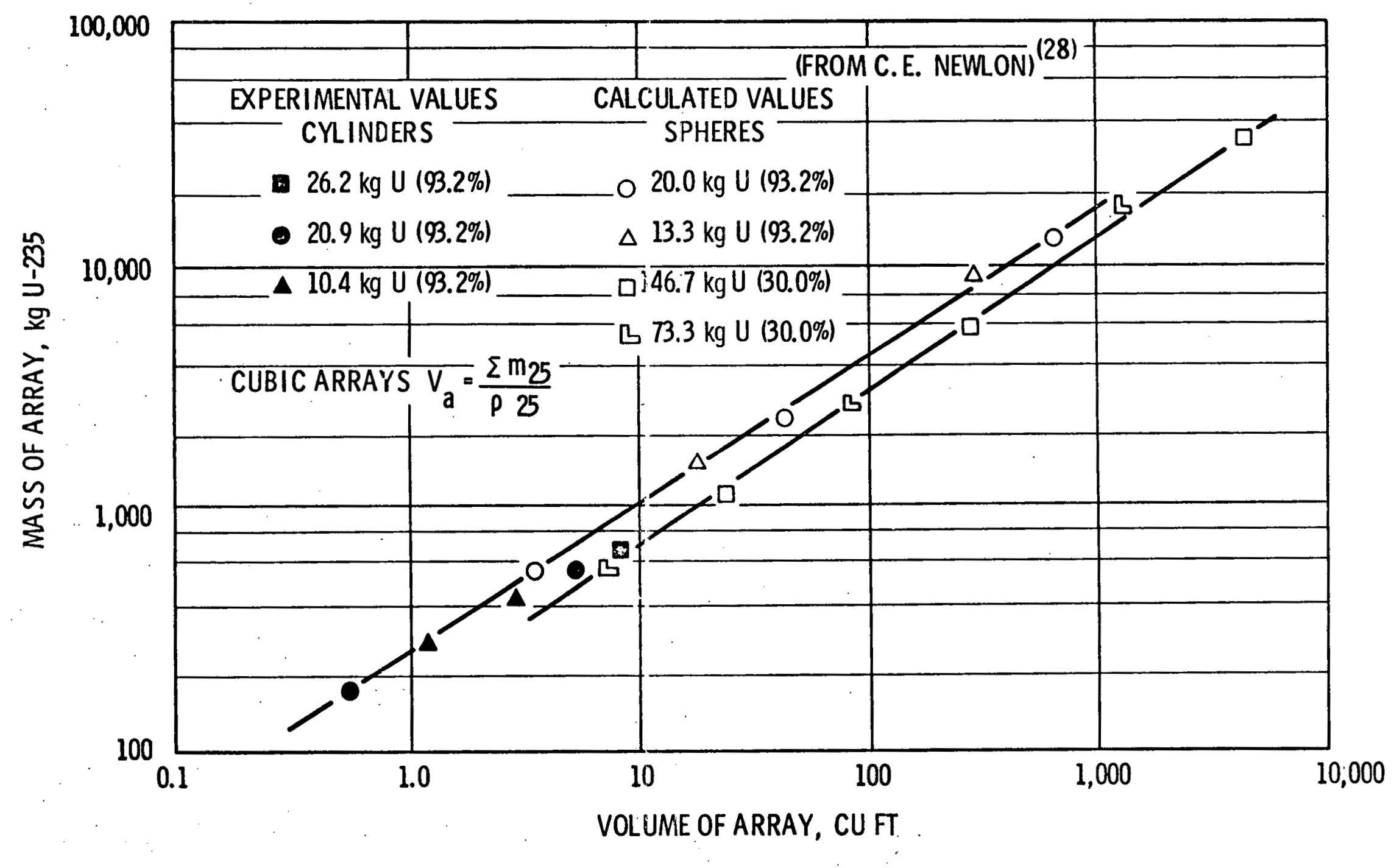

CRITICAL MASS AND VOLUME OF UNREFLECTED METAL ARRAYS 
of nuclear materials. In any operation, not only must subcriticality be established for a single unit, but the degree of subcriticality of the system as a whole; for example, the effects of interconnected and adjacent pipes must be evaluated in processing plants.

An interesting problem concerns the mixing of units within an array. If it has been determined that an array can safely handle $A$ units of metal by itself, and B urits containing dissolved fissile material in solution by itself, then is it logical to assume that these units could be mixed together in the array at the same lattice spacing, providing the combined number were less than either A or B? Surprisingly, the answer can be "no", as borne out by the following simple example (see Fig. 16 and Table II.) (29)

Note that the total number can be significantly less, depending on the pattern of positioning used.

2. Firc (rog. Mist oi Fiooding: A rubentiai of Friple Criticaity)

The previous example was used to show that, on mixing metal and solution units together, the total critical number could be less than that for either of the units when stored separately in the same configuration.

An interesting problem concerns the effect on criticality for an array of interacting units if the water content of the intervening air spaces within the array were increased. This could be brought about by the use of water for fire control or possibly through the use of automatic sprinkler systems in buildings so equipped.

In case of storing mixed oxide fuels of $\mathrm{PuO}_{2}$ and $\mathrm{UNAT}_{2}$, or slightly enriched uranium, three effects (shown schematically in Fig. 17) will be paramount. For purposes of illustration, let us assume the Pu content, or ${ }^{235} U$ content in the $U$, to be less than $5 \%$ such that criticality would not be possible without the addition of moderator, taken in this case to 


\section{CRITICALITY OF MIXED ARRAYS}
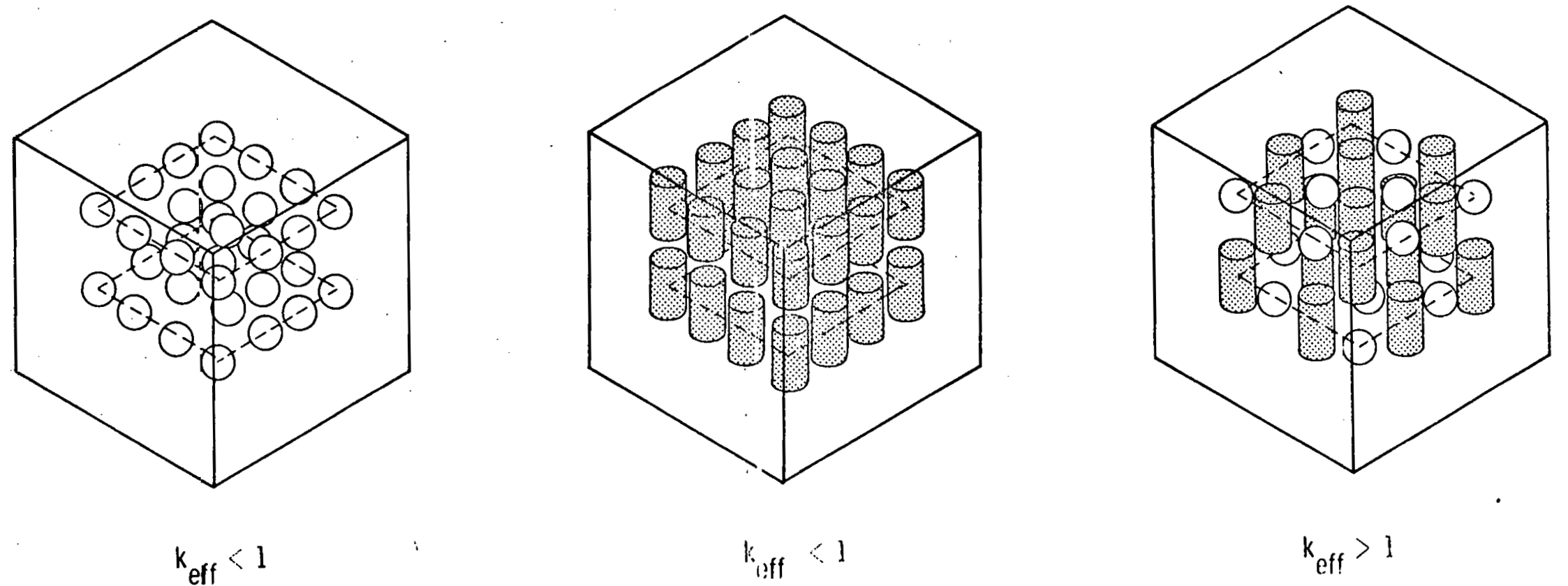

$k_{\text {eff }}<1$

$k_{i f f}<1$

O METAL

7 SOLUTION

FIGURE 16 


\section{TABLE II}

Mixed Units of $3.5 \mathrm{~kg}$ Pu Metal and

$125 \mathrm{~g} \mathrm{Pu}$ in Solution (H/Pu Ratio of 500 )

(Cubic Array)

Spacing Between Units

Center-to-Center

Metal Units Solution Units

'Total

$26 \mathrm{~cm}$

93

None

Number

$26 \mathrm{~cm}$

None

so

93

$26 \mathrm{~cm}$

31

29

$8 \dot{8}$

$26 \mathrm{~cm}$

32

34

60

66 


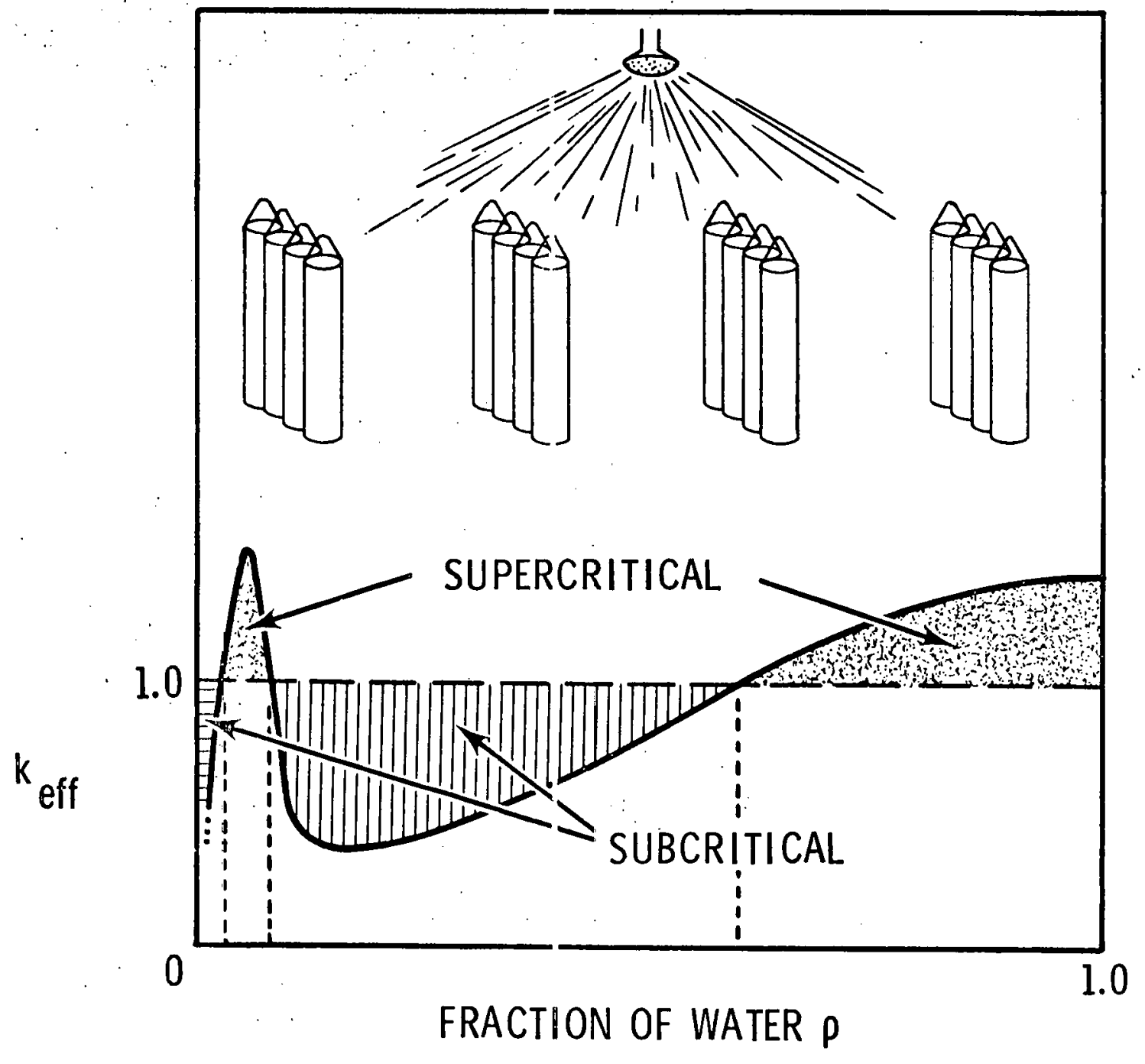

FIRE (FOG, MIST, OR FLOO)DING: THE POTENTIAL OF TRIPLE CRITICALITY IN A STORAGE ARRAY) 
be water. The array is well subcritical initially. . Depending on the fuel composition making up the fuel bundles, and the storage arrangement used it is possible by means of Monte Carlo calculations to generate the type of curve shown. The three effects involve 1) internal moderation of the fuel elements within each fuel bundle, 2) reflection about the array as a whole and also about each individual unit and, 3) interaction between units. Initially, the value of $k_{\text {eff }}$ increases rapidly with increased water density due to internal moderation, external reflection and enhanced interaction. Interaction is enhanced because a small amount of water (typically a few percent of full water density) in the space between units will slow down some of the neutrons in the interaction process. The number of neutrons actually arriving at a second unit will be less, but there will be a higher probability for fission if the neutron energy is reduced. However, with too much moderation or intervening water, too many neutrons will be absorbed between the units and the effect of interaction will be reduced. The value of $k_{\text {eff }}$ is rapidly increased at first, then falls, due to the decrease in neutron interaction. If the surface-to-surface distance between fuel bundles is some $8-12$ in. or more, then, on full flooding, the reactivity of the array would become merely that for a single bundle of fuel immersed. in water. With full flooding, the neutron interaction would be reduced to zero.

Note that in going from the completely dry case to the fully flooded condition, criticality could occur at three different water densities being separated by two subcritical regions of water density. It is important, therefore, for determining the safety of a given storage array that the effect of sprinkler systems, and the use of water for fire control, be fully examined over the full range of water densities. 
K. AN ODDITY OF POISON (THE CONTROL ROD AND THE SOLUTION SPHERE)

In early criticality experiments with Pu solutions it was noted with some surprise that, as a hollow cylinder control rod was moved into the solution of a sphere along its axis, the reactivity actually increased during the initial phases of rod insertion and then reversed itself, contrary to the usual expectation that $k_{\text {eff }}$ should be continuously reduced in such cases. (30) A copy of the chart recording (heretofore unpublished) showing the strange variation in neutron flux with control rod movement is shown in Figure 18. As noted, when the control rod (tube) entered the solution, for spheres that were not quite full, the flux was first observed to rise and then fall. This peculiar behavior might be expected if the rod's poison worth were sma11, for in that case the first portion of the rod is worth more in terms of a volume displacement of solution (the sphere is becoming effectively more fu11) than as a neutron absorber. The effect was estimated to be approximately ten cents from the multiplication curves plotted with the control rod in the full out position and then partially inserted. A perturbation calculation subsequently provided an estimate of 8.4 cents.

L. EVEN-N VS. ODD-N NUCLIDES - A REVERSAL ON THE EFFECTS OF MODERATION

In Figure 1, striking changes were observed to occur in the critical mass as the fissile isotope was diluted with water. The effect of moderation was to enhance criticality and to reduce the critical mass by a factor of ten. This same type of curve prevails for other odd-n nuclides, ${ }^{233} \mathrm{U}$ and ${ }^{235} \mathrm{U}$, etc. We shall now cite examples in which the smallest mass occurs for the unmoderated system, where the effect of water is to prevent, rather than enhance, criticality. 
CONTROL ROD EFFECT ON FLUX LEVEL

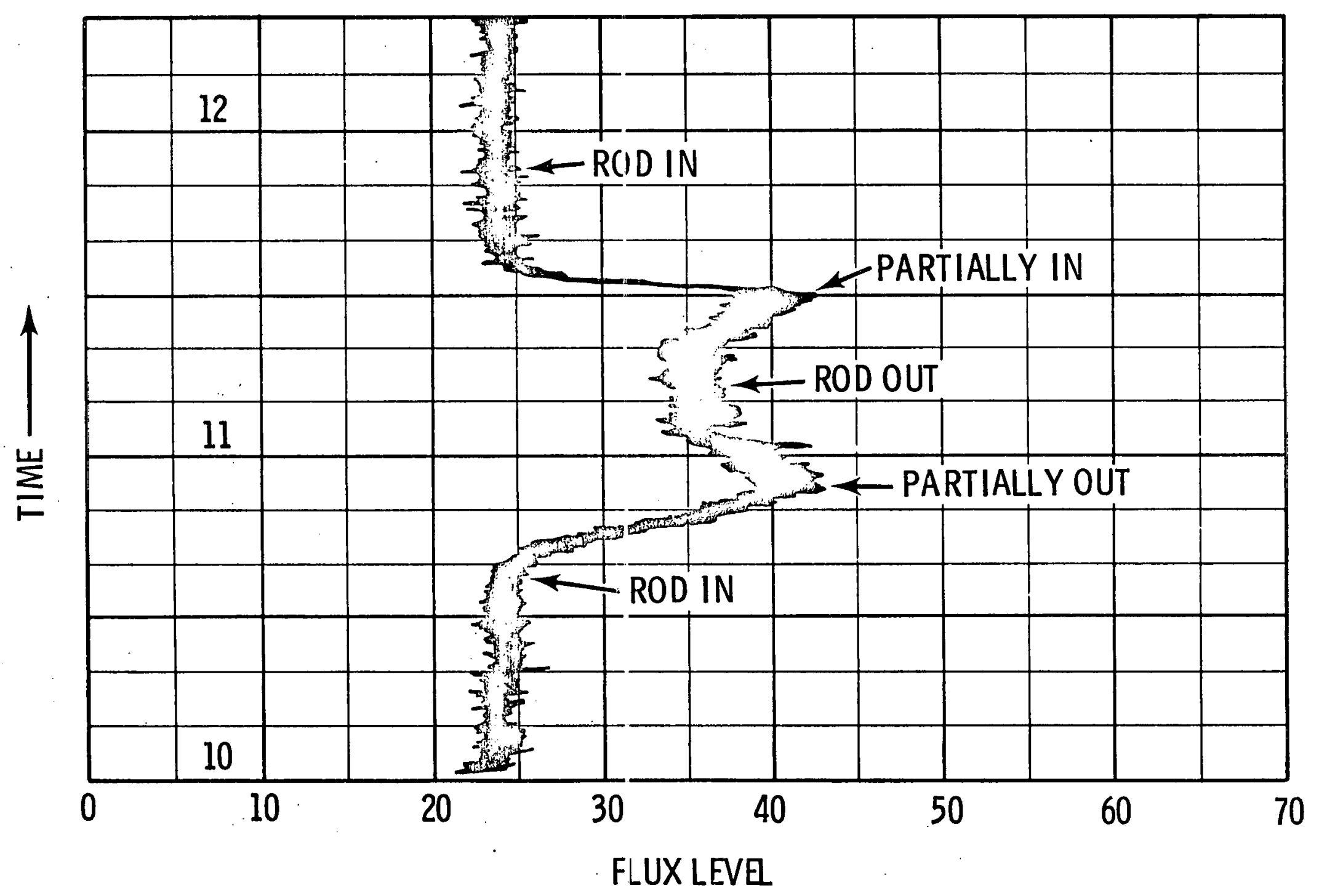

FIGURE 18 
Nuclides such as ${ }_{91}^{231} \mathrm{~Pa},{ }_{93}^{237} \mathrm{~Np},{ }_{94}^{238} \mathrm{Pu},{ }_{94}^{240} \mathrm{Pu},{ }_{95}^{241} \mathrm{Am},{ }_{96}^{244} \mathrm{Cm}$, and ${ }_{98}^{252} \mathrm{Cf}$ contain even numbers of neutrons and all are fissionable, though not fissile. Fissionable nuclei are considered those for which a chain reaction can be set up, with the majority of fissions caused by high energy neutrons. Fissile nuclei are those for which it is possible to set up a chain reaction in which the majority of fissions are caused by thermal or slow neutrons. It follows that the known nuclei which are fissile are fissionable, but not the converse. Calculations show that criticality can be obtained with each of the above listed fissionable even-n nuclides but only under essentially unmoderated conditions. Results of known calculations made to date are summarized in Table III, which also includes critical mass values for the odd-n nuclides. $(31,32)$

In considering the criticality of the even-n nuclides, it is noted that the optimum condition for criticality in terms of minimum mass is reversed. It is reversed in the sense that mixing moderator with an odd-n nuclide (such as ${ }^{239} \mathrm{Pu}$ or ${ }^{241} \mathrm{Pu}$ ) produces the condition resulting in the smallest critical mass. For the even-n nuclides, moderation is found to prevent - rather than enhance criticality. The guaranteed presence of a small amount of moderating diluent would then ensure against accidental criticality and serve as a method of criticality control.

The effect is illustrated in Fig. 19, which gives the value of $k_{\infty}$ and critical radius for ${ }_{93}^{237} \mathrm{~Np}$ as a function of metal concentration. As moderating material is added to a metal-atoms-in-water system, $k_{\infty}$ decreases steadily, as shown in the Figure, from that for a pure metal at $20.45 \mathrm{~kg} / \mathrm{liter}$ through a value of unity at a ${ }^{237} \mathrm{~Np}$ concentration of about 
TABLE IIT

Neutron Fissionability and Criticality

\begin{tabular}{|c|c|c|c|c|c|c|c|c|c|c|c|c|}
\hline \multirow[b]{2}{*}{ Nuclide } & \multirow[b]{2}{*}{ Type } & \multirow[b]{2}{*}{$Z^{2} / A$} & \multirow[b]{2}{*}{$\begin{array}{c}E_{a}^{b} \\
(\mathrm{MeV})\end{array}$} & \multirow[b]{2}{*}{$\begin{array}{c}B_{n}{ }^{\mathrm{C}} \\
(\mathrm{MeV})\end{array}$} & \multirow[b]{2}{*}{$\begin{array}{c}B_{n}-E_{a} \\
(\mathrm{MeV})\end{array}$} & \multicolumn{2}{|c|}{ Criticality Aspects } & \multicolumn{2}{|c|}{$\begin{array}{l}\text { Computed or Measured Critical } \\
\text { Masses of Solution Spheresd; } \\
\text { Thermal Systems at } \\
\text { Optimum Moderation (Ref. 32】 }\end{array}$} & \multicolumn{3}{|c|}{$\begin{array}{c}\text { Computed or Measured Critical } \\
\text { Masses of Metal Spheres: } \\
\text { Fast, Unmoderated Systems } \\
\text { (Rel, 32J }\end{array}$} \\
\hline & & & & & & $\begin{array}{l}\text { Slow-Neutron } \\
\text { Chain Reaction }\end{array}$ & $\begin{array}{l}\text { Fast-Neutron } \\
\text { Chaln Reaction }\end{array}$ & $\begin{array}{l}\text { Bare } \\
(\mathrm{kg})\end{array}$ & $\begin{array}{c}\text { Water } \\
\text { Reflected } \\
(\mathrm{kg})\end{array}$ & $\begin{array}{l}\text { Bare } \\
(\mathrm{kg})\end{array}$ & $\begin{array}{l}\text { Water } \\
\text { Reflected } \\
(\mathrm{kg})\end{array}$ & $\begin{array}{c}\text { Steel } \\
\text { Reflected } \\
(\mathrm{kg})\end{array}$ \\
\hline${ }_{50}^{202} \mathrm{Th}$ & Even-even & 34.91 & 6.0 & 4.8 & -1.2 & No & No & $-\cdots$ & -... & $-\cdots$ & -... & $\ldots$ \\
\hline${ }_{01}^{221} \mathrm{~Pa}$ & Odd-even & 35.85 & 5.94 & 5.6 & -0.34 & No & Indicated & 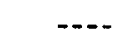 & .... & $-\ldots$ & $\ldots$ & --- \\
\hline${ }_{41}^{232} \mathrm{~Pa}$ & Odd-odd & 35.49 & 5.7 & 6.5 & 0.8 & Questionable & Indicated $^{e}$ & $\ldots$ & $-\cdots$ & $-\therefore$ & $\cdots$ & $\ldots$ \\
\hline${ }_{92}^{233} \mathrm{U}$ & Even-odd & 36.33 & 5.1 & 6.8 & 1.7 & Yes & Yes & 1.2 & 0.59 & 16.5 & 7.3 & $-\ldots$ \\
\hline${ }_{52}^{235} \mathrm{U}$ & Even-odd & 36.02 & 5.2 & 6.5 & 1.3 & Yes & Yes & 1.5 & 0.82 & 49.0 & 22.8 & $\ldots$ \\
\hline${ }_{92}^{238} \mathrm{U}$ & Even-even & 35.56 & 5.7 & 4.8 & -0.9 & No & No & $\ldots$ & $\cdots$ & $\ldots$ & $\cdots$ & $\cdots$ \\
\hline${ }_{93}^{237} \mathrm{~Np}$ & Odd-even & 36.49 & 5.7 & 5.5 & -0.2 & No & Yes' & --- & $\cdots$ & 68.6 & 64.9 & 43.1 \\
\hline${ }_{84}^{238} \mathrm{Pu}$ & Even-even & 37.13 & 5.2 & 5.6 & 0.4 & No & Yes' & --- & $\cdots$ & 7.2 & 5.6 & 4.5 \\
\hline${ }_{24}^{209} \mathrm{pu}_{\mathrm{u}}$ & Even-odd & 36.97 & 4.8 & 6.4 & 1.6 & Yes & Yes & 0.905 & 0.53 & 10.0 & 5.42 &.-- \\
\hline${ }_{94}^{240} \mathrm{Pu}$ & Even-even & 36.82 & 5.3 & 5.24 & -0.06 & No & Yes ${ }^{i}$ & -..- & $\ldots$ & 158.7 & 148.4 & 96.4 \\
\hline${ }_{94}^{211} \mathrm{Pu}$ & Even-odd & 36.66 & 5.0 & 6.3 & 1.3 & Yes $^{f}$ & Yes ${ }^{t}$ & $\cdots$ & 0.26 & -... & 6.0 & $\ldots$ \\
\hline${ }_{95}^{2+11} \mathrm{Am}$ & Odd-even & 37.54 & 5.4 & 5.5 & 0.1 & No & Yes' & $\cdots$ & -..- & 113.5 & 105.3 & 71.4 \\
\hline${ }_{i s}^{212} \mathrm{~A}, \mathrm{n}$ & Odd-odd & 37.29 & 5.1 & 6.4 & 1.3 & Yes ${ }^{\prime}$ & Indicated $^{e}$ & -.-- & 0.023 & $\ldots$ & -.. & -... \\
\hline${ }_{85}^{243} \mathrm{Am} \mathrm{m}$ & Odd-even & 37.14 & 5.5 & 5.4 & -0.1 & No & Indicated & $\ldots$ & --- & $\ldots$ & $\ldots$ & $\ldots$ \\
\hline${ }_{90}^{241} \mathrm{Cm}$ & Even-odd & 37.93 & 4.5 & 6.8 & 2.3 & Yes $^{\prime}$ & Indicatede & $\ldots$ & 0.213 & $\cdots$ & $\ldots$ & $\cdots$ \\
\hline${ }_{96}^{24} \mathrm{Cm}$ & Even-even & 37.77 & 5.0 & 5.5 & 0.5 & No & Yes' & $\ldots$ & -..- & 23.2 & 22.0 & 14.2 \\
\hline${ }_{4 \rightarrow j}^{2,45} \mathrm{Cm}$ & Even-oxld & 37.62 & 4.6 & 6.5 & 1.9 & Yes $^{f}$ & Indicated $\mathrm{d}^{e}$ &.-- & 0.042 & & & \\
\hline${ }_{9 i}^{247} \mathrm{Cm}$ & Even-odd & 37.31 & 4.7 & 6.2 & 1.5 & Yes $^{f}$ & Indicated $^{e}$ & -... & 0.159 & -... & $\ldots$ & -..- \\
\hline${ }_{88}^{249} \mathrm{Cl}$ & Even-odd & 38.57 & 4.3 & 6.6 & 2.3 & Yes' & Indicated $^{e}$ & $\ldots$ & 0.032 & .... & $\ldots$ & $\cdots$ \\
\hline${ }_{98}^{250} \mathrm{Cf}$ & Even-even & 38.42 & 4.7 & 5.1 & 0.4 & No & Indicated $^{e}$ & $\cdots$ & $-\cdots$ & $=-$. & .... & $\cdots$ \\
\hline${ }_{88}^{251} \mathrm{Cf}$ & Even-odd & 38.26 & 4.4 & 6.2 & 1.8 & Yes' & Indicated $^{e}$ & 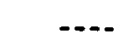 & 0.010 & ---- & $\cdots$ & $\cdots$ \\
\hline${ }_{88}^{252} \mathrm{Cf}$ & Even-even & 38.11 & 4.8 & 4.8 & 0.0 & No & Indicated $^{e}$ & $\cdots$ & -... & $\ldots$ & $\ldots$ & $-\cdots$ \\
\hline${ }_{8 \theta}^{254} \mathrm{Es}$ & Odd-odd & 38.59 & 4.7 & 6.0 & 1.3 & Indicated ${ }^{e}$ & Indicated $^{e}$ & $\cdots$ & $\cdots$ & --- & $\ldots$ & -.-- \\
\hline
\end{tabular}

${ }^{b} E_{a}=$ activation energy for fission (fissior. time $10^{-14} \mathrm{sec}$ ); $E_{a}$ is $0.9 \mathrm{MeV}$ lass than fission barrier (Ref. 33)-

${ }^{c} B_{n}=$ neutron binding energy for nuclide of mass $A+1$ (Ref. 33)

Minimum mass for homogeneous aqueous solutions.

'No question concerning the possibility of criticality, but no calculations are known to have been made.
Computed (see Ref. 31 ) 


\section{CRITICALITY OF \\ HOMOGENEOUS $237 \mathrm{NP}$-WATER SYSTEMS}

H/M ATOMIC RATIO

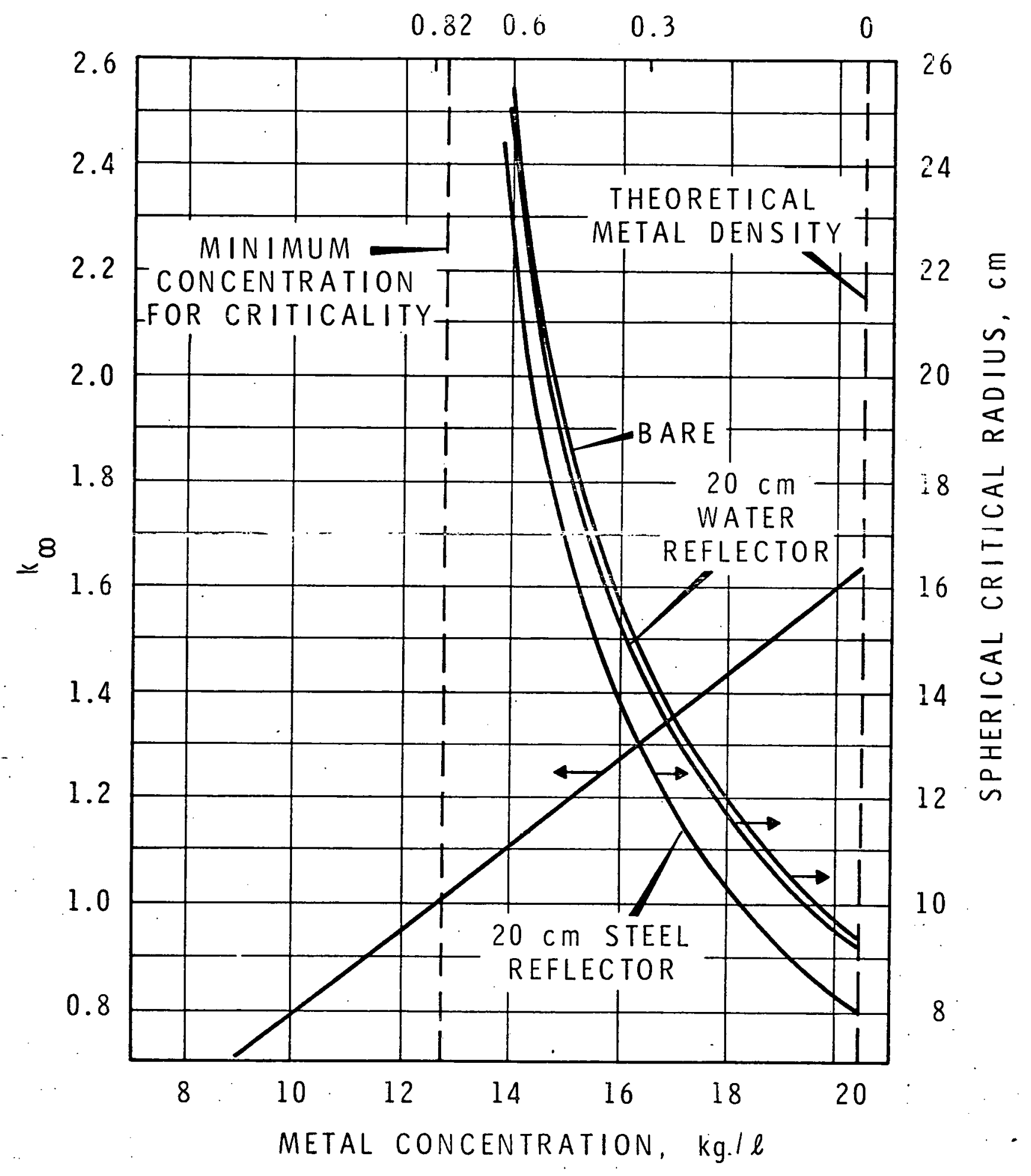

FIGURE 19 
$12.7 \mathrm{~kg} /$ liter. Below $12.7 \mathrm{~kg} / 1$ iter, the reproduction factor for an infinite system $\left(k_{\infty}\right)$ becomes less than unity and criticality is no longer possible. Over the concentration range where criticality is possible, the critical radius for a steel-reflected sphere of metal atoms in water varies uniformly from a minimum of $8.0 \mathrm{~cm}(43 \mathrm{~kg})$ for the pure metal to a maximum value approaching infinity as the minimum critical concentration of $12.7 \mathrm{~kg} / 1 \mathrm{iter}$ is approached.

The effect of energy degradation also becomes evident in the reflector savings of such a system. A good moderating material, such as water, returns neutrons of reduced energy to the core. In the case of ${ }_{93}^{237} \mathrm{~Np}$, many of the reflected neutrons are degraded in energy below the effective fission threshold and, hence, these returning neutrons contribute little to the fission process.

\section{THE INFINITE SEA CONCENTRATION}

The limiting critical concentration in water is defined as that uniform concentration of the fissile isotope that is required to obtain a $k_{\infty}$ of unity. In the case of plutonium the "infinite sea" concentration is $7.2 \pm 0.1 \mathrm{~g} / 1 \mathrm{iter}$ (H/Pu ratio $\simeq 3680)$. (8) At this point, about half of the neutrons released in fission are absorbed in the diluent $\left(\mathrm{H}_{2} \mathrm{O}\right)$, since

$$
k_{\infty}=2.08 t=1 \text {, where } 2.08 \text { is the } n \text { for } \mathrm{Pu} \text {. }
$$

It should be remembered that it is not the concentration per se that is important, but rather the ratio of absorbing atoms to fissile atoms which determines this limit, and is the controlling factor.

\section{Criticality in Earth}

Let us consider the discharge of dilute plutonium solutions to earth (such as in the case of an underground waste trench or sludgefilled vessel). Initially, there would be no. problem of criticality, 
providing the Pu concentration in the aqueous solution were uniform and less than $7.2 \mathrm{~g} / \mathrm{liter}$, for below this concentration $\mathrm{k}$ would be less than unity even for an infinitely large system.

Let us assume the Pu to build up uniformly and be held as in a matrix within the sand or soil. Subsequently, the soil begins to dry out and our earth system could become supercritical, even though the concentration of $\mathrm{Pu}$ in the soil were significantly less than $7.2 \mathrm{~g} / 1 \mathrm{iter}$ !

This seemingly anomalous happening may be explained as follows: It is well known that a dilute aqueous solution containing less than $7.2 \mathrm{~g} \mathrm{Pu} /$ iter could be contained in a large vessel and be well subcritical initially, and subsequently achieve criticality through the simple process of evaporation. In this case, however, the fissile atom density would automatically increase beyond $7.2 \mathrm{~g} / 1$ iter as the water evaporated and the solution concentrated.

The problem of criticality is unique as given herein, because the density of fissile atoms could, theoretically, remain unchanged as the soil dried and yet criticality could occur at concentrations significantly below $7.2 \mathrm{~g} / 1 \mathrm{iter}$. The reason is that the soil displaces water and the absorption cross section for "pure" sand is relatively small. Thus, as Pu builds up in the soil (perhaps from solutions containing only milligram/liter quantities initially) a concentration could be achieved that is well below $7.2 \mathrm{~g} / 1$ iter, yet on simple evaporation of water from the soil (at a later date) the system might well become critical. Thus, an abandoned crib could (under the proper circumstances) become critical months or even years iater. Note that such a system would likely be autocatalytic in the event of criticality - for the reproduction factor would be further 
enhanced as the heat from fission evaporated water from the system. It should be noted, also, that under the conditions given, $k_{\text {eff }}$ could be reduced by the readdition of water to the system, or the system would be made further subcritical on flooding.

The bases for these conclusions are presented in Figures 20 and 21 and come from an interesting series of calculations by K. R. Ridgway and R. D. Carter on "Criticality Prevention Parameters of Plutonium in Soils." (34)(35)

The calculations were made for plutonium-soil mixtures of two different void fractions (the void fraction is the space available within the soil that might be filled with plutonium-water mixtures). Void fractions of 30 and 40 volume percent were assumed, and both fully-saturated, and one-third saturated, soil parameters were calculated. The soil composition used was as follows:

\section{TABLE IV}

HANFORD SOIL COMPOSITIONS, WEIGHT PERCENT

\begin{tabular}{cc} 
Component & Dry Soil \\
\cline { 1 - 2 } $\mathrm{SiO}_{2}$ & 81.0 \\
$\mathrm{Al}_{2} \mathrm{O}_{3}$ & 6.0 \\
$\mathrm{Fe}_{2} \mathrm{O}_{3}$ & 2.0 \\
$\mathrm{FeO}$ & 2.0 \\
$\mathrm{CaO}$ & 4.0 \\
$\mathrm{MgO}$ & 2.0 \\
$\mathrm{~K}_{2} \mathrm{O}$ & 1.0 \\
$\mathrm{Na}_{2} \mathrm{O}$ & 1.0 \\
$\mathrm{H}_{2} \mathrm{O}$ & 1.0 \\
&
\end{tabular}

Full soil density, no voids: $2.43 \mathrm{~g} / \mathrm{cm}^{3}$ 


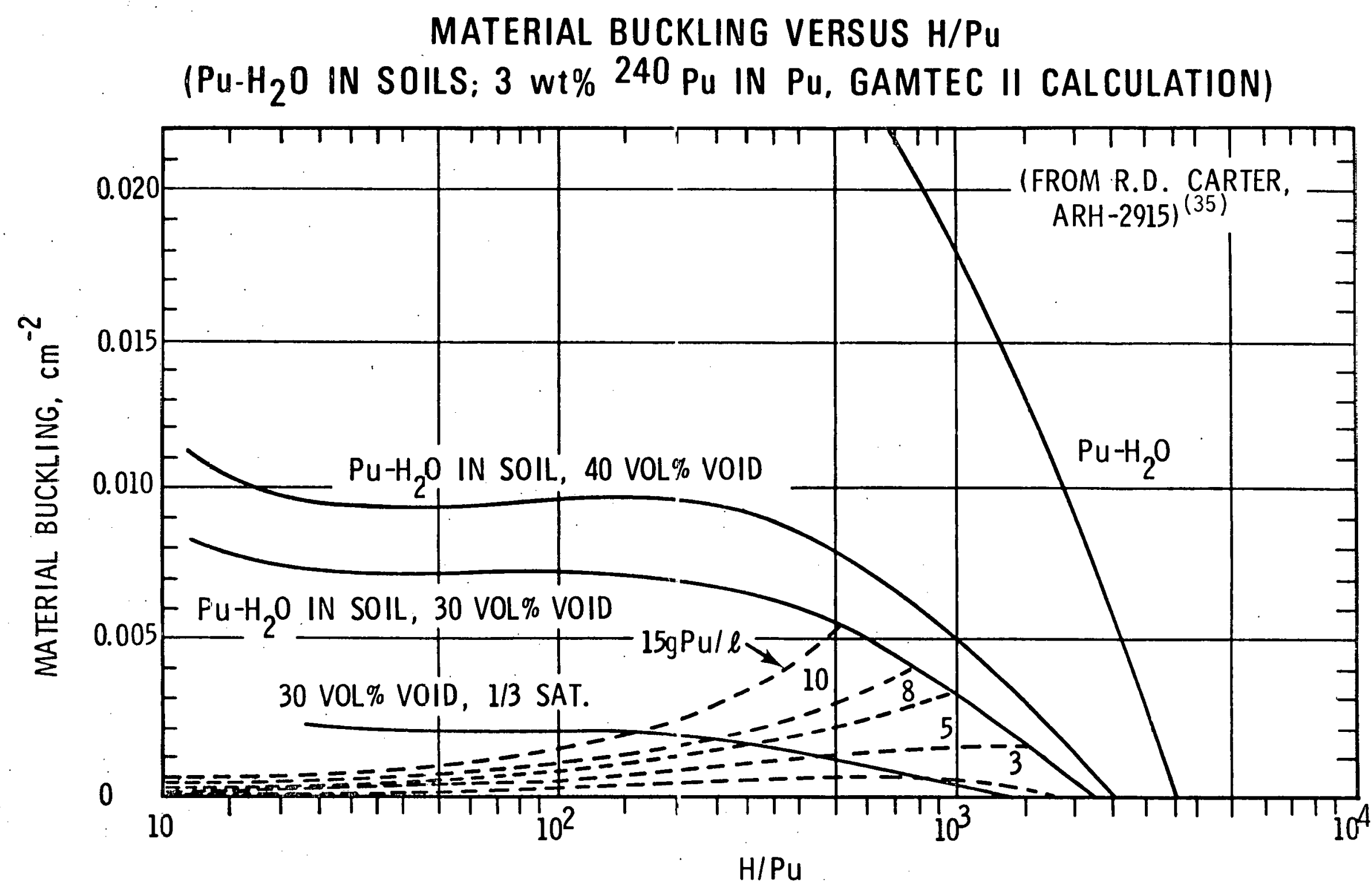

FIGURE 20 
$k \propto$ VERSUS $H / P u$

(Pu-H ${ }_{2} \mathrm{O}$ IN SOILS; 3 wt $\%{ }^{240} \mathrm{Pu}$ IN Pu; GAMTEC $\|$ CALCULATION.)

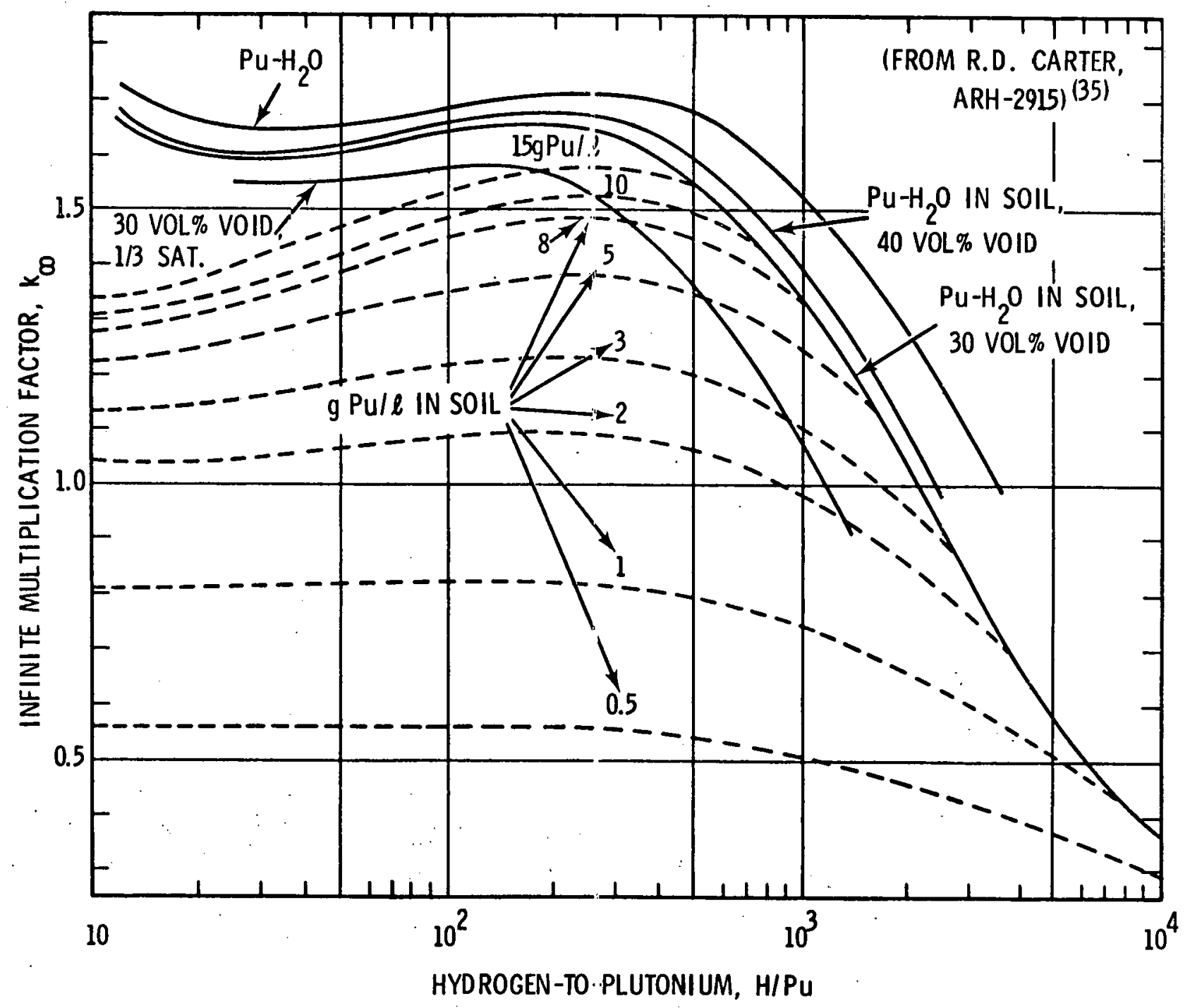


The calculations for soil (assuming 30 vol\% void) fully saturated show the value of $k_{\infty}$ to be about 1.3 at a concentration of $7.2 \mathrm{~g} \mathrm{Pu} / 1$ iter (critical mass about $4.2 \mathrm{~kg} \mathrm{Pu}$ ). If water were to be removed, however, such as through the process of evaporation, $k_{\infty}$ would subsequently increase and go through a maximum value $\geq 1.4$ during the process. This means that criticality would be possible at concentrations below $7.2 \mathrm{~g} / 1 \mathrm{iter}$ perhaps as low as $1.75 \mathrm{~g} / 1$ iter in the soil with the proper dryness $(\mathrm{H} / \mathrm{Pu} \sim 200)$.

2. The Universe

Pertaining to the "infinite sea" concentration and criticality in earth, it was noted that it was not the concentration per se that was the controlling factor, but rather the ratio of fissile atoms to absorbing atoms that was paramount. We may now speculate as to whether there is any lower limit on the critical concentration in the absence of any absorbing atoms; for example, in infinite space - or the "ether". Although of academic interest only, there is technically such a limit.

In this situation, the infinite multiplication constant is the ratio of neutron generation rate by fission to the rate of neutron loss by both $\beta$-decay and absorption within a critical system whose lower limit of nuclei density is determined by the radioactive decay constant of the neutron. Under these conditions the critical equation (assuming the neutrons are at the average energy of fission, $\sim 2 \mathrm{MeV}$ ) becomes, $\mathrm{n} v \mathbb{N} \cdot \sigma_{a} n=$ $\mathrm{n} \vee \mathrm{N} \sigma_{a}+\lambda_{B} \mathrm{n}$ where the losses (on the right) come from absorption as well as $\beta$-decay of the neutron, since the neutron is radioactive (half-life about 12 minutes) with a mean 1 ife of about 17 minutes. In the above, $\lambda_{\beta}$ is the decay constant for $\beta$ emission by the neutron, taken as $9.6 \times 10^{-4} \mathrm{sec}^{-1}$. The relativistic velocity for the neutron 
with $2 \mathrm{MeV}$ of energy is about $2 \times 10^{9} \mathrm{~cm} / \mathrm{sec}$, or some $12,200 \mathrm{mi} / \mathrm{sec}$. Assuming 2 barns for the absorption cross section of Pu at $2 \mathrm{MeV}$, and taking $n$ as 2.85 , the mean free path, $\lambda=\frac{1}{\mathrm{No}}$, is estimated to be $3.8 \times 10^{12} \mathrm{~cm}$. The latter corresponds to a distance about 100 times that between the earth and the moon:

The density of the fissile atoms (or "infinite ether" concentration) would, under these circumstances, be incomprehensibly small - a fraction of a billionth of a gram/cc. Under these conditions (if Pu were considered as fuel) there would be only about $1 \alpha$-decay/cc every $8 \mathrm{sec}$. To be more precise, it should be considered that some of the fast neutrons will scatter inelastically per collision event. These neutrons will move with less velocity and, hence, will have more time to decay before encountering another Pu atom. In other words, the effect of inelastic scattering is to increase the number of neutrons lost by B-decay. To compensate for this effect, the nuclei density would have to be slightly increased. The criticality equation(s) become considerably more complex under the latter consideration.

N. NATURE'S ANOMALY

One of the strangest happenings to have been uncovered since the first man-made criticality (December 2, 1942, by E. Fermi and co-workers) was the discovery of nature's criticality in the Republique of Gabonaise. This event is believed to have taken place some one-hundred million years ago, and the reaction is thought to have remained critical for perhaps one million years.

This strange phenomenon was brought to light when it was noted that the ${ }^{235} \mathrm{U}$ content from the Oklo mine was much less than normal, ranging in values down to as low as $0.440 \%$ in some places where the concentration 
of uranium in the mine exceeded $20 \%$ by weight; also, in some cases, a few samples of very slightly enriched uranium were actually found, making the situation even more puzzling. Now, the isotopic composition of natural uranium is known to be remarkably constant throughout the world. The ${ }^{235} U$ atomic percentage is $0.7200 \pm 0.0006 \%$, with the possible variation being less than the experimental accuracy.

After a detailed and careful analysis, it was concluded that the modifications in the isotopic compositions of the uranium could only be the consequence of nuclear fission reactions. It was found that, in all samples in which the uranium was depleted, the isotopic composition of the rare earth elements differed completely from that of naturally occurring elements and was strikingly representative of fission product yields.

The analysis suggests that the uranium deposited and concentrated at

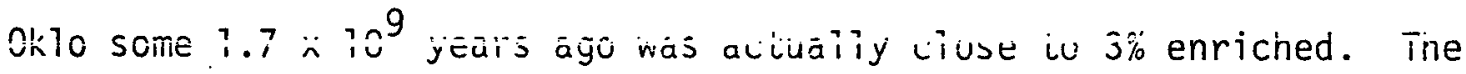
amount of fissionable material consumed during criticality was computed to be of the order 1 to 1.5 tons of ${ }^{235} \mathrm{U}$. The corresponding energy produced amounted to 2 to $3000 \mathrm{MW}-\mathrm{yr}$. This prehistoric reactor would have been somewhat akin to today's 1 ight water reactor with a burn up of the order 20,000 MWd/T. The cvidence for the event is most convincing, as a result of the fine analysis made, and there can be little doubt that the reaction actually took place - some one-hundred-million years prior to man's first criticality.

0. "SMALL MASS" CONCEPTS

1. Thin Foils and Nonabsorbing Low Temperature Moderators

It is now known how, in principle, to obtain a critical configuration with less than an ounce of ${ }^{239} \mathrm{Pu}$, or with only about one ounce of ${ }^{235} \mathrm{U}$. (37) These quantities are only about $1 / 20$ of the 
minimum critical masses prescribed for these nuclides in criticality safety handbooks or safety guides. The study by R. S. 01son and M. A. Robkin was predicated on the surprising observation that an infinite slab of material with $n>1$ immersed in an infinite nonabsorbing moderator would have an essentially zero critical thickness.

As reported by 01 son and Robkin, a series of calculations were made with single sheets of ${ }^{235} \mathrm{U}$ and ${ }^{239} \mathrm{Pu}$ metal foils reflected by thick regions of $\mathrm{D}_{2} \mathrm{O}$. The temperature of the core and $\mathrm{D}_{2} \mathrm{O}$ was lowered to $4^{\circ} \mathrm{K}$ to rethermalize neutrons striking the core (thin fuel sheets) and to take advantage of the absorption characteristics of the fuel. Under these circumstances, a minimum critical mass of only $35 \mathrm{~g}$ was obtained for the ${ }^{235} \mathrm{U}$ foil, and only $22 \mathrm{~g}$ for the ${ }^{239} \mathrm{Pu}$ foil. The results demonstrate the theoretical possibility of obtaining remarkably small critical masses with the fissile material in the form of a single foil $\simeq 0.2 \mathrm{mil}$ thick. (See R. S. 01son Thesis for Master's Degree in Nuclear Engineering, University of Washington, 1970, for details.) (38)

2. The Laser-Induced Micro-Explosion

As noted previously, the critical mass of an unreflected sphere will vary inversely as the square of the density, $M_{c} \sim \rho^{-2}$. For example, if two systems, differing only in density, were critical ( $k_{\text {eff }}=$ unity) but the density of the first was 100 times that of the second, its critical mass would be only $1 / 10,000$ that of the second.

It has recently been suggeșted that it may be possible, by means of powerful laser beams or intense relativistic electron beams, to compress a small fissionable sphere, of the order of a $\mathrm{mm}$, into a 
highly supercritical assembly. ${ }^{(39)(40)}$ Pressures up to $10^{12} \mathrm{~atm}$ comparable with the pressure in the center of the sun are believed achievable with advanced giant lasers or electron beams irradiating the small pellet simultaneously from all sides. Under these circumstances the fissile material is said to be compressed to about 250 times normal density. It is further reported by $W$. Seifritz and J. Ligou that a pellet containing $0.2 \mathrm{~g} \mathrm{Pu}\left(95 \%{ }^{239} \mathrm{Pu}\right.$ and $5 \%{ }^{240} \mathrm{Pu}$ of radius $\left.1.35 \mathrm{~mm}\right)$ reflected by a $1.77 \mathrm{~mm}$ thick $L i^{6} \mathrm{D}$ shell, could be compressed to a supercritical state having $k_{\text {eff }} \simeq 1.25$ if a laser pulse-energy of some 4.7 MJ were absorbed in the outer otlative layer. (40) The number of fissions that would occur during the $0.8 \mathrm{nsec}$ burst is given as $2.33 \mathrm{x}$ $10^{20}$, which is equivalent to an energy release of 1.61 tons TNT (a burnup of nearly $50 \%$ would be achieved). Further, in the case of a T-D reflector the initial fissionable pellet diameter could be even smaller (containing on 1 y $10^{-2} \mathrm{~g} \mathrm{Pu}$ ).

The preceding illustration constitutes an example for the effect of ultra-extreme density change on criticality. It would be of great interest, should it prove feasible during the next few years, to perform a successful irradiation confirming the above. Under the conditions stated it would be possible to reduce the critical mass of $\mathrm{Pu}$ (or other fissionable material) by tremendous factors; in the case of $\mathrm{Pu}$, some one-half million below that required for Pu metal at normal density.

\section{P. BEYOND CALIFORNIUM - THE "MICRO" CRITICAL MASS}

1. Beyond Callforntum

Increased binding energy at closed, or in the region near-closed, shells of nucleons results in increased stability of the nucleus. (41)(42) She11 closures beyond lead now are predicted at $Z=114$, and $N=184$. 
Due to the additional binding, doubly-closed she11, superheavy "magic" nuclei, if somehow formed, might be relatively stable; whereas, nuclei lying in the region beyond the end of the periodic table prior to reaching this "island of stability" would not exist with any significant half-life. This leads to the prediction of the relatively stable superheavy element $\frac{298 \mathrm{X}}{114}$, and to others with closed or nearly closed, neutron and proton shells. (42)

J. R. Nix has predicted some of the properties associated with the fission of the hypothetical superheavy nuclei. (42) A few of these properties are included in Table $V$.

\section{2. "Micro" Critical Mass}

We may now conjecture as to the possible minimum critical mass of superheavy, doubly-closed shell magic element(s) $x$, as yet undiscovered, but theoretically predicted. In making this "oualitative" estimate we have assumed a nucleus one neutron short of the magic number; i.e., a nucleus with an odd number of neutrons but in the region of a closed shell.

$$
\begin{aligned}
114^{\mathrm{X}}: \text { critical radius } & \sim 3.44 \mathrm{~cm} \\
\text { critical volume } & \sim 0.17 \mathrm{l} \\
\text { critical mass } & \sim 0.5 \mathrm{~g}
\end{aligned}
$$

Assuming minimum concentration of $\sim 3 \mathrm{~g} / 2$

in aqueous solution; water-reflected sphere. 
TABLE $V$

Properties of Superheavy Nuclei

- Fissioning

Nucleus

Energy Release Number of Neutrons

Per Fission

Per Fission

Lifetime

$298 x$

$317 \mathrm{MeV}$

10.5

$294 x$

$290 \mathrm{MeV}$

10.6

$\sim 10^{9}$ years $^{*}$

*Total half-life from decay by spontaneous fission, $\alpha$ decay, B decay, etc. 
Q. THE POWER REACTOR - FOUR-BILLION HATTS AND SUBCRITICAL

At the entrance of the $\mathrm{N}$-Reactor, on the Hanford Reservation, there is a sign which informs the visitor he is about to enter the largest nuclear steam generating plant in the world. As of August, 1974, the dual-purpose $\mathrm{N}$-Reactor held the Free World's record of steam production for electrical generation at 26.5 billion $\mathrm{kW}-\mathrm{hr}$. Yet, this reactor, even if generating 4 billion watts of thermal power in constant mode, is technically subcritical, as the reproduction factor would be fractionally less than unity. This reactor, as is true of all others when at constant power level, will be found to be riding on neutron source multiplication where the origin of the source neutrons is not the chain reaction itself, but rather from $\alpha-n$ reactions taking place in the reactor's core material and from spontaneous fission in $238 \mathrm{U}$ or $240 \mathrm{Pu}$, etc. The multiplication rate is given approximately by

$$
M=\frac{s+s k_{e f f}+s k_{e f f}^{2}+\cdots}{s}=\frac{1}{1 \cdot k_{e f f}} \text {, for } k_{e f f}<1 \text {. }
$$

If, somehow, it were possible to remove the source neutrons, the power level would slowiy fall to zero unless control rod adjustments were made to compensate. The multiplication rate at full "subcritical" power level could be in the range $10^{11}$ to $10^{13}$, or up to some ten trillion.

R. CONCLUSIONS

The foregoing examples serve, if for no other purpose, to illustrate the futility of attempting to set up a few rigorous, general rules pertaining to the factors affecting criticality, and to illustrate the complexity of criticality itself.

It is shown that there can be as many as three different critical concentrations with the same critical volume, and perhaps four different fuel concentrations having the same critical mass. Contrary to the usual expectation, the sphere, after all, may not be the configuration of least mass; 
the reflected cube may be somewhat less under certain circumstances. In some cases, the effect of added scatterers can significantly reduce the critical dimension; whereas, in others the result can be precisely the opposite. It is noted that reducing the core density can, under some circumstances, actually decrease the critical mass, contrary to the usual expectation that the mass will be increased. Surprising as it may seem, a system with $k_{\infty}<$ unity might be made critical by reducing the core size and adding a finite reflector of $\mathrm{D}_{2} \mathrm{O}$, etc. (in the latter case $k_{\text {eff }}>\mathrm{k}_{\infty} !$ ). In some cases, the effect of moderation results in the smallest critical mass; whereas, in others (depending on the evenness or oddness of the nuclide) the effect is again precisely the opposite. We have seen where a homogeneous

- aqueous mixture of ${ }^{235} \mathrm{U}$ and ${ }^{238} \mathrm{U}$ could have a smaller ${ }^{235} \mathrm{U}$ critical mass (over a limited concentration range) with low enriched uranium than if the uranium were fully enriched $\left(93.5 \mathrm{wt} \%{ }^{235} \mathrm{U}\right)$, and that an unmoderated interacting array of metal units (spheres of $30 \mathrm{wt} \%{ }^{235} \mathrm{U}$ ) might have a lower critical density than an array of fully enriched uranium spheres, of identical volume, and thus a smaller critical ${ }^{235} \mathrm{U}$ mass in the array. There is an example wherein the effect of inserting a neutron absorbing rod into a Pu-solution-bearing sphere is to cause the reactivity to initially increase rather than decrease.

Pressures up to $10^{12} \mathrm{~atm}$, comparable with the pressure in the center of the sun, are now believed achievable with advanced giant lasers or electron beams which could change the density of a small pellet of fissionable material under irradiation by a factor of some 250 , thus making it possible to achieve a supercritical event in a small pellet of Pu containing as little as $10^{-2} \mathrm{~g}$ $\mathrm{Pu}$. One of the more interesting events in the annals of criticality was the discovery of a possible prehistoric chain reaction (Nature's Anomaly) that took place in the Republique of Gabonaise some 100 million years ago with 3 wt\% $235 \mathrm{U}$ enriched uranium. 
Finally, it is interesting to recall that, in the presence of inherent neutron sources, even the power reactor will be technically subcritical $\left(k_{\text {eff }}<1\right)$ when operating in a constant power mode at any power level. The list continues, and there are doubtless many other seemingly apparent anomalies that can be cited in the field of criticality.

S. ACKNOWLEDGEMENTS

The author kindly acknowledges the work of others, too numerous to mention individually, from which he so liberally borrowed in preparing this paper on anomalies of criticality.

This paper is based on work performed under U. S. Atomic Energy Commission Contract AT(45-1)-1830. 


\section{REFERENCES}

(1) R. D. CARTER, G. R. KIEL, and K. R. RIDGWAY, Criticality Handbook, Atlantic Richfield Hanford Company, ARH-600, Vol. I to III, Richland, Washington $(1969 / 71)$.

(2) W. THOMAS and W. WEBER, Handbuch zur Kritikalitatt, Lehrstuhl für Reaktordynamik und Reaktorsicherheit der Universität Munchen, Garching (1970/72).

(3) J. W. WAChter, M. L. Bailey, T. J. CAgle, W. T. MEe, R. H. Pletz, F. G. WELFARE, and B. J. YOUNGBLO0D, Y-12 Plant Nuclear Safety Handbook, Y-1272 (1973) 190 p., N.S.A. 17 (1963) Nr. 32292; TID-4500 (20th Ed.) (1963).

(4) H. C. PAXTON, J. T. THOMAS, A. D. CALLIHAN, and E. B. JOHNSON, Critical Dimensions of Systems Containing $235 \mathrm{U},{ }^{239} \mathrm{Pu}$, and ${ }^{233} \mathrm{U}$, TID-7028 (1964).

(5) Authority Health and Safety Branch, United Kingdom Atomic Energy Authority: Handbook of Criticality Data, Vol. I, AHSB(S) Handbook 1, 1967; Handbook of Experimental Criticality Data, AHSB(S) Handbook 5,

Part I, Chapters 1 to 4,1967

Part II, Chapters 5 and 6, 1968, Pari iis, Cilapiers 7 to 10 , 1508.

(6) E. D. CLAYTON, "Plutonium Criticality Experiments," Physics Today, 18, 46-52 (1965).

(7) C. R. RICHEY, "Theoretical Analyses of Homogeneous Plutonium Critical Experiments," Nuclear Science and Engineering, 31, 32-39 (1968)

(8) C. R. RICHEY, "Re-examination of the Value for the Minimum Critical Concentration of ${ }^{239} \mathrm{Pu}$ in Water, "submitted as Technical Note for publication in Nuclear Science and Engineering (1974).

(9) S. R. BIERMAN and E. D. CLAYTON, "Critical Experiments with Homogeneous $\mathrm{PuO}_{2}$-Polystyrene at $50 \mathrm{H} / \mathrm{Pu}$, Nuclear Technology, 15, 5-13 (1972).

(10) L. E. HANSEN, S. R. BIERMAN and E. D. CLAYTON, "Criticality of Mixed $\mathrm{PuO}_{2}-\mathrm{UO}_{2}$ Systems," Physics Research Quarteriy Report April, May, June 1969, BNWL-1150, Batte1le Memorial Institute, Pacific Northwest Laboratories (August 1969): 
(11) S. R. BIERMAN and E. D. CLAYTON, "Critical Experiments With Unmoderated Plutonium 0xide," Nuclear Technology, 11, 185 (1971).

(12) S. R. BIERMAN, L. E. hANSEN, R. C. LlOYd, and E. D. ClaytOn, "Critical Experiments With Homogeneous $\mathrm{PuO}_{2}$-Polystyrene at $5 \mathrm{H}: \mathrm{Pu}$, "Nuclear Applications, 6, 23 (1969).

(13) G. E. WHITESIDES and N. F. CROSS, "KENO - A Multigroup Monte Carlo Criticality Program," CTC-5, Union Carbide Corporation (1969).

(14) S. R. BIERMAN, Private Communication, December, 1973.

(15) W. R. STRATTON, Criticality Data and Factors Affecting Criticality of Single Homogeneous Units, LA-3612, Los Alamos Scientific Laboratory (1967).

(16) R. C. LANE, C. PARKER, F. BROWN and D. G. STEVENSON, "Nuclear Safety Aspects of the Design and Operation of a Plant for the Production of Fast Reactor Fuel," Criticality Control of Fissile Materials, Proceedings of a Symposium, Stockho1m, 1-5 November, 1965, I.A.E.A., Vienna (1966).

(17) E. R. WOODCOCK, "Fundamentals of Criticality Control," Criticality Control

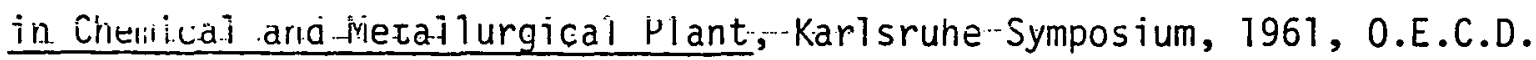

(18) MAKOTO IWAI, "Effect of Added Scatterers on Nuclear Criticality, " Journal of Nuclear Science and Technology, 7 (6) 291-299 (1970).

(19) K. D. LATHROP, DTF-IV - A Fortran-IV Program for Solving the Multigroup Transport Equation With Anisotropic Scattering, LA-3373, Los Alamos Scientific Laboratory (1965).

(20) C. M. NICHOLLS, E. R. WOODCOCK, and A. H. GILLIESON, "Criticality," Nuclear Science and Technology I, Chemical Processing of Reactor Fuels, 394, Academic Press, Inc., New York (1961).

(21) C. B. MILLS, "Reflector Moderated Reactors," Nuclear Science and Engineering, 13, 301 (1962).

(22) L. B. ENGLE and W. R. STRATTON, "Critical Dimensions of Homogeneous Spheres Containing ${ }^{235} \mathrm{U},{ }^{238} \mathrm{U}$, and Carbon for Various $\mathrm{C} /{ }^{235} \mathrm{U}$ Ratios and ${ }^{235} \mathrm{U}$ Enrichments," LA-3883-MS, Los Alamos Scientific Laboratory (1968). 
1. (23) M. L. BLUMEYER, The Effects of Moderating Reflectors on Undermoderated Negative Buckling Cores, a thes is submitted in partial fulfillment of the requirements for an MS degree in Nuclear Engineering, University of Washington, 1968.

- (24) G. A. Linenberger, J. D. ORndOFF and H. C. PAXTON, "Enriched-Uranium Hydride Critical Assemblies," Nuclear Science and Engineering, 7, 44-57 (1960).

(25) H. C. PAXTON, Discussion on "Fundamentals of Criticality Control," Criticality Control in Chemical and Metallurgical Plant, Karlsruhe Symposium, 1961, O.E.C.D.

(26) W. A. REARDON and F. R. CZERNIEJEWSKI, "A Study of Idealized Plutonium Metal Dissolvers and the "Always Safe" Conditions," Transactions American Nuclear Society, 6, 170 (1963).

(27) H. F. HENRY and C. E. NEWLON, K-1141, "Water Boiler Calculations of Critical Parameters," Carbide and Carbon Chemicals Company, K-25 Plant, Oak Ridge, Tennessee, August 13, 1954.

- (28) C. E. NEWLON, "The Elements of Neutron Interacting Arrays," Proceedings International Symposium for Packaging and Transportation of Radioactive Materials, January $12-15,1965$, SC-RR-65-98 (Sandia Corporation and U. S. Atomic Energy Commission, Albuquerque, New Mexico).

(29) Report of the IAEA Group of Consultants on Criticality Control in the Transport of Fissile Materials, Panel on Revision of Regulations for the Safe Transport of Radioactive Materials, Vienna, 11-22 March, 1963.

1, (30) R. C. LLOYD, E. D. CLAYTON, and W. A. REARDON, "Operating Experience in the Hanford Plutonium Critical Mass Facility," Transactions American Nuclear Society, $\underline{5}, 76$ (1962).

(31) E. D. CLAYTON and S. R. BIERMAN, "Criticality Problems of Actinide El ements," Actinides Reviews, I, 409-432 (1971).

- (32) E. D. CLAYTON, "Fissionability and Criticality: From Protactinium to Cal ifornium and Beyond," Technical Note, Nuclear Science and Engineering, 52, 417-420 (1973). 
(33) R. VANDENEOSCH and G. T. SEABORG, "Consideration on the Probability of Nuclear Fission", The Physical Review, 110, 507 (1958.

(34) K. R. RIDGWAY and R. D. CARTER, Criticality Prevention Parameters of Plutonium in Soils, ARH-2622, Atlantic Richfield Hanford Company, Richland, Wasington (1972).

(35) A. E. SMITH, Nuclear Reactivity Evaluations of 216-2-9 Enclosed Trench, ARH-2915, Atlantic Richfield Hanford Company, Richland, Washington (1973).

(36) R. NAUDET, "Rapport De Synthese Sur Le Phenomene D'OK10," Bulletin d'Informations Scientifiques et Techniques, №. 193 (June 1974).

(37) R. S. OLSON and M. A. ROBKIN, "A New Small Mass Critical Configuration," Transactions American Nuclear Society, 13, 669 (1970).

(38) R. S. OLSON, A Theoretical Investigation of a Possible New Small Mass Critical Configuration, a thesis submitted in partial fulfillment of the requirements for an MS degree in Nuclear Engineering, University of Washington, 1970.

(39) F. WINTERBERG, "The Possibility of Micro-Fission Chain Reactions and Their Applications to the Controlled Release of Thermonuclear Energy," Z. Naturforsch, $\underline{28 \mathrm{a}}, \underline{6}, 900$ (1973).

(40) W. SEIFRITZ AND J. LIGOU, "Laser-Induced Thermonuclear Micro-Explosions Using Fissionable Triggers," Transactions American Nuclear Society, 18, 18 (1974).

(41) W. D. MYERS and W. J. SWIATEKI, "Anomal ies in Nuclear Masses," in ARKIV FOR FYSIK, Proceedings of the Sysekil Symposium, 1966, Volume 36, No. 43, 343-352 (1967).

(42) J. R. NIX, "Predictions for Superheavy Nuclei," Physics Today, 25, 30-38 (1972). 